\title{
ZORNIA J. F. GMEL. (LEGUMINOSAE - PAPILIONOIDEAE - AESCHYNOMENEAE) NO ESTADO DE SÃO PAULO ${ }^{1}$
}

\author{
Alan Sciamarelli ${ }^{2}$ \\ Ana Maria G. de Azevedo Tozzi ${ }^{3}$
}

Recebido em 18/7/95. Aceito em 7/11/96.

RESUMO - (Zornia J.F.Gmel. (Leguminosae - Papilionoideae - Aeschynomeneae) no Estado de São Paulo). Este trabalho teve como objetivo levantar e estudar as espécies do gênero Zornia J.F.Gmel. que ocorrem no Estado de São Paulo. Foi confirmada a ocorrência de 9 espécies: Zornia gardneriana Moric., Z. virgata Moric., Z. cryptantha Arechav., Z. ramboiana Mohlenbr., Z. glabra Desv.,Z. reticulata Sm., Z. latifolia Sm., Z. curvata Mohlenbr. e Z. gemella (Willd.) Vogel. Zornia paniculata N.F. Mattos foi considerada sinônimo de Z. virgata. Para as espécies foi confeccionada uma chave para identificação, descriçōes, comentários, ilustraçōes e mapas de distribuição geográfica.

Palavras-Chave: Zornia, Leguminosae, Papilionoideae, Aeschynomeneae

ABSTRACT - (Zornia J.F.Gmel. (Leguminosae - Papilionoideae - Aeschynomeneae) in the state of São Paulo). This work presents an inventory of the species of the genus Zornia J.F.Gmel. in State of São Paulo. Nine species have been recognized: Zornia gardneriana Moric., Z virgata Moric., Z. cryptantha Arechav., Z. ramboiana Mohlenbr., Z. glabra Desv., Z. reticulata Sm., Z. latifolia Sm., Z curvata Mohlenbr. and Z. gemella (Willd.) Vogel. Zornia paniculata N.F. Mattos was considered synonymous of Z. virgata. An identification key for these species as well their descriptions, comments, illustrations and updates geographic distribution data were provided.

Key words: Zornia; Leguminosae, Papilionoidae, Aeschynomeneae

\section{Introdução}

O gênero Zornia contém 75 espécies e apresenta uma distribuição pantropical (Mohlenbrock 1961). Na América Latina existem 33 espécies nativas, sendo 12 exclusivas do Brasil (Mohlenbrock 1961). Ocorrem desde a Amazônia até os pampas do Rio Grande do Sul e predominam em campos e cerrados "sensu lato".

1 Parte de dissertação de Mestrado de A. Sciamarelli. Curso de Pós-graduação em Biologia Vegetal do Instituto de Biologia da Universidade Estadual de Campinas.

2 Bolsista da CAPES (Demanda Social)

3 Depart. Botânica. IB, Universidade Estadual de Campinas, C. P. 6109. CEP. 13083-970. Campinas, SP 
Houve um certo interesse em se desenvolver pesquisas visando a utilização de espécies de Zornia em associação com gramíneas para a nitrificação do solo. Contudo, os estudos de algumas espécies de Zornia, promovidos pelas Estações Experimentais do Instituto Agronômico de Campinas, mostraram que elas produzem pouca matéria vegetal e poucas sementes por área plantada, inviabilizando sua exploração econômica. Aranha et al. (1972) e Lorenzi (1982) citam algumas espécies como invasoras de áreas de cultivo.

O gênero Zornia, descrito por Gmelin (1791), foi revisado por Bentham (1859), que o dividiu em duas seções, Zornia sect. Myriadenus (Desv.) Vogel e Zornia sect. Zornia, e posteriormente por Mohlenbrock (1961), que elevou estas seções à categoria subgenérica, estabelecendo ainda três seções paraZornia subgen.Zornia: Zornia sect. Isophylla Mohlenbr., Zornia sect. Anisophylla Mohlenbr. e a seção típica.

O conceito específico de Bentham (1859) foi bastante abrangente e como consequiência ele propos a sinonimização de diversas espécies até então descritas, reconhecendo ao todo 8 espécies, dentre as quais Zornia diphylla (L.) Pers. com 14 variedades. Por outro lado, o conceito de Mohlenbrock (1961) foi mais restrito, de forma que muitas das variedades de $Z$. diphylla foram elevadas ao nível específico. Esta diferença de conceituação específica tem causado muitos problemas nas identificações atuais, pelo fato de que os limites das espécies, como estabelecidos por Mohlenbrock (1.c.), são muitas vezes mal definidos e sobrepostos.

Outros trabalhos taxonômicos sobre o gênero restringem-se à descrição de novos taxa ou a floras regionais, como os de Bacigalupo \& Troncoso (1977), Burkart (1939, 1952), Fawcett \& Rendle (1920), Lewis (1987), Lewis \& Owen (1989), Mattos (1975), Reynolds \& Holland (1989), Vanni (1981), Velazquez \& Orsini (1991) e Turril \& Milne-Redhead (1956).

Para o Estado de São Paulo foram citadas por Mohlenbrock (1961) as seguintes espécies: Zornia virgata Moric., Z. vestita Mohlenbr., Z. cryptantha Arechav., Z. ramboiana Mohlenbr., Z pardina Mohlenbr. var. pardina, Z reticulata $\mathrm{Sm}$., Z. latifolia Sm., Z. curvata Mohlenbr. e Z. gemella (Willd.) Vogel. Além destas, Mattos (1975) descreveu uma espécie nova com base em material coletado em São Paulo, $Z$. paniculata N.F. Mattos, e Rocha et al. (1979) registraram a ocorrência de Z. gracilis DC., atualmente sinonimizada com Z. latifolia, e de $Z$. aff. orbiculata Mohlenbr.

Em vista da dificuldade de identificação específica, da escassez de trabalhos taxonômicos do grupo e da rápida diminuição da área de vegetação nativa no Estado de São Paulo se faz necessário o estudo das espécies de Zornia dessa região. Este estudo visou o inventário das espécies de Zornia no Estado de São Paulo e a atualização das informações morfológicas e ecológicas destas espécies.

\section{Material e métodos}

O material botânico para a execução deste trabalho é proveniente dos herbários nacionais e estrangeiros, de coletas próprias, depositadas no Herbário UEC, e de observações no campo. 
Na sinonímia não constam os nomes listados por Mohlenbrock (1961), com exceção do basiônimo.

A descrição das espécies baseou-se no material estudado. A terminologia da morfologia está de acordo com Radford et al. (1974) e as medidas representam a amplitude da variação observada. A ocorrência no Estado de São Paulo foi obtida de coletas e de dados das etiquetas das exsicatas. A citação do material examinado se restringe ao Estado de São Paulo.

A chave de identificação foi baseada, principalmente, em caracteres morfológi$\cos$ vegetativos, complementados por aqueles relacionados às flores e frutos.

São utilizadas as seguintes abreviações: fl., flores; fr., frutos; bt., botões; s/col., sem coletor(es); s/n, sem número de coletor; s/ loc., sem localidade e compr., de comprimento.

\section{Resultados e discussão}

Descrição do gênero

Zornia J.F. Gmel., Systemae Naturae 2: 1076-96. 1791. Espécie tipo: Z. bracteata (Walt.) J.F. Gmel.

Plantas perenes, arbustivas a subarbustivas. Ramos prostrados ou eretos, glabros, seríceos, velutinos ou híspidos. Folha com 2 ou 4 folíolos opostos, peciolada, raque nula ou curta; folíolos das folhas 4-folioladas espatulados, ovado-lanceolados ou oblongo-lanceolados, pontuados, glabros a seríceos, das 2-folioladas, os inferiores variam de orbiculares a oval-elípticos, obovados ou oblongo-lanceolados e os superiores são geralmente oval-lanceolados, glabros a seríceos, pontuados ou não; estípulas 2, laterais, peltado-lanceoladas, auriculadas, pontuadas ou não, glabras a seríceas, geralmente ciliadas; estipelas ausentes. Inflorescências espiciformes, axilares ou mais raramente terminais, congestas ou laxas, eixos glabros a seríceos. Bractéolas pareadas, peltadas, orbiculares a lanceoladas, glabras a seríceas e geralmente hirsutas nas margens. Cálice verde ou paleáceo, pontuado ou não, glabro a seríceo, tubo curto, bilobado com lacínios desiguais. Corola amarela com guias de néctar vináceos; estandarte oval-depresso, ungüiculado, glabro ou pubérulo no ápice; asas menores que o estandarte, falcadas ou oblongas, auriculadas, ungüiculadas e com esculturas lunado-lameladas; pétalas da quilha pouco menores que as asas, falcadas, unidas pelos bordos formando um tubo; androceu monadelfo, curvo, com 10 estames dimorfos, alternadamente com anteras orbiculares, versáteis e lanceoladas, dorsifixas; ovário quase séssil com 2 a muitos óvulos, estilete curvo. Lomento 2-8-articulado, glabro a seríceo, pontuado ou não, com acúleos pubérulos ou não. Sementes comprimidas, elípticas, quadrangulares ou retangulares, micrópila entre o hilo e a saliência da radícula, hilo geralmente circular ou elíptico, embrião reto ou curvo, cotilédones carnosos, aproximadamente quadrangulares, pontuados ou não. 
De acordo com a classificação infragenérica (Mohlenbrock 1961), não foi constatada a ocorrência de espécies de Zornia subgen. Myriadena para o Estado de São Paulo e, dentre aquelas do subgênero típico, somente foram encontradas espécies de duas das três seções existentes (Zornia sect. Zornia e Zornia sect. Anisophylla).

Chave para a identificação dos subgêneros e seções de Zornia

1. Flores solitárias, pediceladas; folha 4-foliolada Zornia subgen. Myriadena

1. Flores sésseis em inflorescências racemosas, axilares ou terminais; folha 2- ou 4foliolada

2. Folha 4-foliolada Zornia subgen.Zornia

2. Folha 2-foliolada Zornia sect. Zornia

3. Planta com folhas basais com folíolos de forma igual a dos folíolos das folhas apicais (não presente em São Paulo) Zornia sect. Isophylla

3. Planta com folhas basais com folíolos de forma diferente daquela dos folíolos das folhas apicais, geralmente menores Zornia sect. Anisophylla

Chave para identificação das espécies de Zornia ocorrentes no Estado de São Paulo

1. Folhas com 4 folíolos

2. Arbustos eretos com mais de $60 \mathrm{~cm}$ de altura; folíolos de $40-60 \times 10 \mathrm{~mm}$; bractéolas 15-20 x 9-10mm

2.Z. virgata.

2. Subarbustos geralmente prostrados, com menos de $60 \mathrm{~cm}$ de altura; folíolos de 8 $30 \times 3-5 \mathrm{~mm}$; bractéolas 5-7 $\times 4-9 \mathrm{~mm}$

1. Folhas com 2 folíolos

2.Z. gardneriana.

3. Bractéolas maiores que $11 \mathrm{~mm}$ de compr.

4. Folíolos, ramos e bractéolas com indumento seríceo ou velutino

5. Estípulas de $13 \mathrm{~cm}$ compr., com 7 nervuras longitudinais; espiga de até $7 \mathrm{~cm}$ compr.

4.Z. ramboiana.

5. Estípulas de $22 \mathrm{~cm}$ compr., com 9-11 nervuras longitudinais; espiga mais longa que $10 \mathrm{~cm}$ compr.

4. Folíolos, ramos e bractéolas com outro tipo de revestimento

3.Z. cryptantha.

6. Folíolos superiores oblanceolados; bractéolas glabras a esparso-estrigosas, ovais, com aurícula oval-lanceolada; inflorescência laxa; fruto com acúleos seríceos

5.Z. glabra.

6. Folíolos superiores lanceolados; bractéolas glabras a tomentosas, oblongolanceoladas, com aurícula triangular; inflorescência congesta; fruto raramente com acúleos

3. Bractéolas menores que $11 \mathrm{~mm}$ de compr.

6. Z. reticulata.

7. Raque da inflorescência mais longa que $3 \mathrm{~cm}$ compr.; bractéolas geralmente sem aurículas, entretanto quando presentes menores que $1 \mathrm{~mm}$ compr.; ramos prostrados e laxos 7. Z. latifolia. 
7. Raque da inflorescência mais curta que $1,5 \mathrm{~cm}$ compr.; bractéolas com aurículas maiores que $1 \mathrm{~mm}$ e até $3 \mathrm{~mm}$ compr.; subarbusto denso, ereto ou prostrado

8. Folíolos superiores oblongo-lanceolados, face adaxial glabra; bractéolas oval-lanceoladas; fruto curvo 8.Z. curvata.

8. Folíolos superiores ovados ou elíptico-lanceolados, face adaxial esparsoserícea; bractéolas elíptico-lanceoladas; fruto reto..Z. gemella (Willd.)Vogel

\section{Zornia J.F.Gmel. subgen. Zornia sect. Zornia}

As principais características das plantas que compõem a seção Zornia são as flores agrupadas em inflorescências espiciformes e as folhas 4-folioladas, com os folíolos opostos muito próximos entre si.

Em São Paulo esta seção está representada por apenas uma espécie nativa, Zornia virgata, e uma introduzida, Z. gardneriana.

1. Zornia gardneriana Moric., Pl. Nouv. Amer.: 131. 1844.

Figura 1 A-D e Figura 2

Subarbusto até $60 \mathrm{~cm}$ altura. Ramos prostrados e eretos, glabros a densoestrigosos. Estípulas ovais, agudas, 9-12 x 2-3 mm; com aurícula basal de 3-4 mm compr., pontuadas, margens setosas, com 3-5 nervuras; folhas 4-folioladas; pecíolo 5-20 mm compr., peciólulos 2-3 mm compr., glabros a setosos; folíolos 8-30 x 3-5 $\mathrm{mm}$, oval-lanceolados a oblongo-lanceolados, ápice obtuso, base aguda, papiráceos, pontuados, glabros no limbo e com nervura principal setosa em ambas as faces, venação broquidódroma e reticulada em ordens superiores, nervuras imersas em ambas as faces. Espigas laxas, raque 1-2 cm compr., setosa, pontuada. Bractéolas 5-7 x 4-9 mm, orbiculares; aurícula basal $1 \mathrm{~mm}$ compr., assimétrica, ciliadas, pontuadas, com 5-6 nervuras. Cálice $3 \mathrm{~mm}$, lacínios 4, ciliados, 4-nervado. Lomento 3-5-articulado; artículo 1,5 × $2 \mathrm{~mm}$, glabro com acúleos de base larga e pouco seríceo, não reticulado, com ou sem pontuações. Sementes com hilo circular; carúncula com 2 saliências circulares; embrião reto, submediano, cotilédone obovado, compresso, não pontuado, $1,6 \times 1 \mathrm{~mm}$.

Apesar de ser uma espécie de distribuição restrita ao Nordeste brasileiro (Piauí, Ceará e Rio Grande do Norte) e Mato Grosso (Mohlenbrock 1961), foi também encontrada cultivada na região de Matão (São Paulo) e já disseminada pelas proximidades do município (Fig. 2). Zornia gardneriana foi introduzida em São Paulo para pesquisas de interesse econômico, por apresentar mais massa vegetal que as outras espécies 2-folioladas.

Facilmente reconhecida entre as espécies que ocorrem em São Paulo, pois Zornia gardneriana faz parte do grupo de Zornia 4 -foliolada, representado no Estado somente por ela e por Z. virgata. Desta, por sua vez, Z. gardneriana se diferencia no 


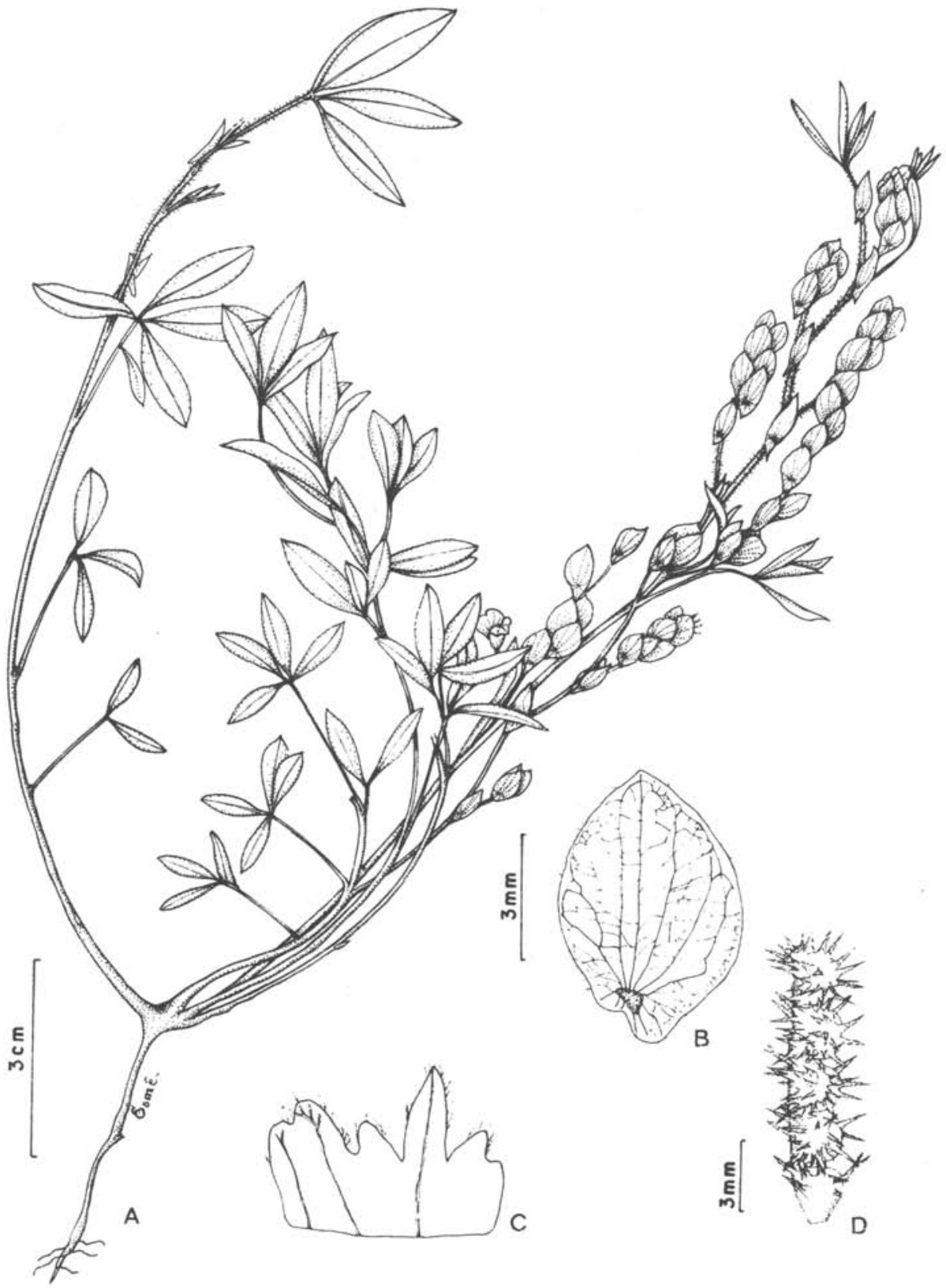

Figura 1.Zornia gardneriana Moric. A - aspecto geral do ramo, B - bractéola, C - cálice, D - lomento (Mattos IAC 21942). 


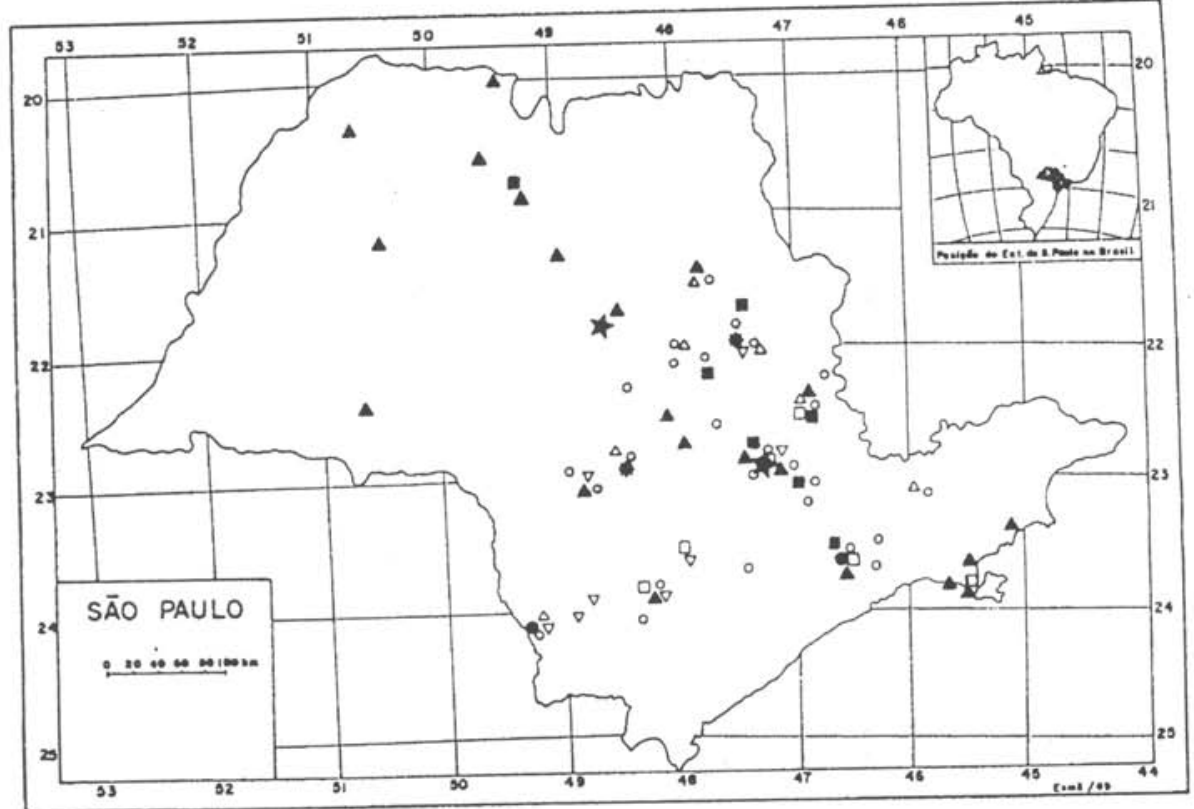

Figura 2. Distribuição geográfica de material examinado de Zornia J.F.Gmel.

^ Zornia gardneriana Moric.,

¿ Zornia curvata Mohlenbr..

A Zornia latifolia Sm.,
* Zornia virgata Moric.,

- Zornia gemella (Willd.) Vogel,

- Zornia ramboiana Mohlenbr. . $\nabla$ Zornia cryptantha Arechav.,

$\triangle$ Zornia glabra Desv.,

O Zornia reticulata $\mathrm{Sm}$.

hábito subarbustivo e, principalmente, nas bractéolas e lomento, pois Z. virgata é uma planta arbustiva, com bractéolas muito maiores e lomento com um ou dois artículos.

Zornia gardneriana é próxima deZ. brasiliensis, espécie do nordeste do Brasil, diferindo por apresentar indumento mais esparso nos ramos, folíolos e bractéolas e por ter o fruto com reticulações e glândulas.

Material Examinado: São Paulo: Matão, 18/I/1963, C. Moura 114, fr. (SP); Matão, 30/ IV/1964, D.O. Morris 227, fr. (SP); Nova Odessa, 14/III/1970, H.B. Mattos, fl., fr. (IAC 21492); s/ loc., s/data, Haudin 45353, fl., fr.(SP).

2. Zornia virgata Moric., Pl. Nouv. Amer.: 129.1844.

Z. paniculata N. F. Mattos, Loefgrenia 63: 1. 1975, syn. nov.

Figura 2 e Figura 3 A-D

Arbusto $60 \mathrm{~cm}$ de altura. Ramos eretos, glabros. Estípulas $10-20$ x 3-4 mm, ovadas e agudas; aurícula basal 3-5 mm compr., glabras, muito pontuadas, com 4-5 nervuras longitudinais. Folhas 4 -folioladas; pecíolo $3 \mathrm{~mm}$ compr., glabro; folíolos 40$60 \times 10 \mathrm{~mm}$, oblanceolados, ápice e base agudos, cartáceos, glabros, muito pontuados, 
venação emersa na superfície abaxial e imersa na adaxial. Espigas com raque de 30-50 mm compr., glabra. Bractéolas 15-20 x 9-10 mm, elípticas; aurícula basal 3-5 x 3-4 $\mathrm{mm}$, glabras, margens esparso-ciliadas, muito pontuadas, com 6-8 nervuras longitudinais. Cálice $3 \mathrm{~mm}$ compr., densamente pontuado, 12-nervado, ciliado. Lomento 1-2articulado; artículo $6 \times 4 \mathrm{~mm}$, híspido, acúleos 3-4 mm compr., pontuado, reticulado. Sementes com hilo elíptico; rafe e carúncula ausentes; embrião curvo, submediano; cotilédone oblongo, pontuado, $3 \times 2,5 \mathrm{~mm}$.

Esta espécie, estabelecida por Moricand (1844), é bem delimitada apresentando muitos caracteres diagnósticos, como as folhas com quatro folíolos, presentes apenas em poucas espécies de Zornia. Separa-se de Z. gardneriana pelo hábito, um bom caráter diagnóstico, pois a planta pode atingir 1,5 metros de altura, com ramos pouco ramificados, além de seus frutos e bractéolas muito peculiares.

O holótipo de Zornia paniculata, M. Kuhlmann s/n. (SP), foi observado e considerado uma variação esperada dentro da amplitude morfológica de $Z$. virgata, sendo portanto sinonimizada.

Em São Paulo, Zornia virgata ocorre nos cerrados de Botucatu e de Pirassununga (Fig. 2). Em outros Estados, também é encontrada em cerrados, como em Brasília (DF). Citada para Minas Gerais, Mato Grosso e Goiás (Mohlenbrock 1961).

Material Examinado: São Paulo: Botucatu, 22/IV/1986, H. Bicudo et al. 984 fl., fr. (UEC); Botucatu, 20/V/1986, H. Bicudo et al. 1149, fr. (SP, UEC); Pirassununga, 18/ V/1976, B.L. Morretes s/n, fl., fr. (SPF 34648); Pirassununga, 23/IX/1980, A. Custódio Filho 328, fl., fr. (SP); Província de São Paulo, 1848, A.F. Respules 421, fl. (US).

Zornia subgen. Zornia sect. Anisophylla Mohlenbr., Webbia 16(1): 78. 1961. Espécie tipo: Zornia latifolia $\mathrm{Sm}$.

Todas as plantas agrupadas na seção Anisophylla possuem inflorescências espiciformes e folhas 2 -folioladas, sendo que os folíolos da parte superior da planta são de forma diferente da inferior, sendo geralmente mais estreitos e mais longos, tornando-se lanceolados a lineares. Neste grupo estão incluídas as espécies do complexoZornia diphylla (L.) Pers. Em São Paulo foram reconhecidas 7 espécies, das quais apenas $Z$. cryptantha e $Z$. ramboiana podem ser facilmente identificadas; as demais são separadas com base em caracteres mais ou menos contínuos, difíceis de serem evidenciados.

3. Zornia cryptantha Arechav., Anal. Mus. Nac. Montevideo 3: 358. 1901.

Z. latifolia Sm. var. villosa Malme, Ark. Bot. 23A(13): 25. 1931.

Z. villosa (Malme) Herter, Revista Sudamer. Bot. 7: 210. 1943 ,

Z. lanata Mohlenbr., Webbia 16(1): 98. 1961.

Figura 2 e Figura 4 A-E 

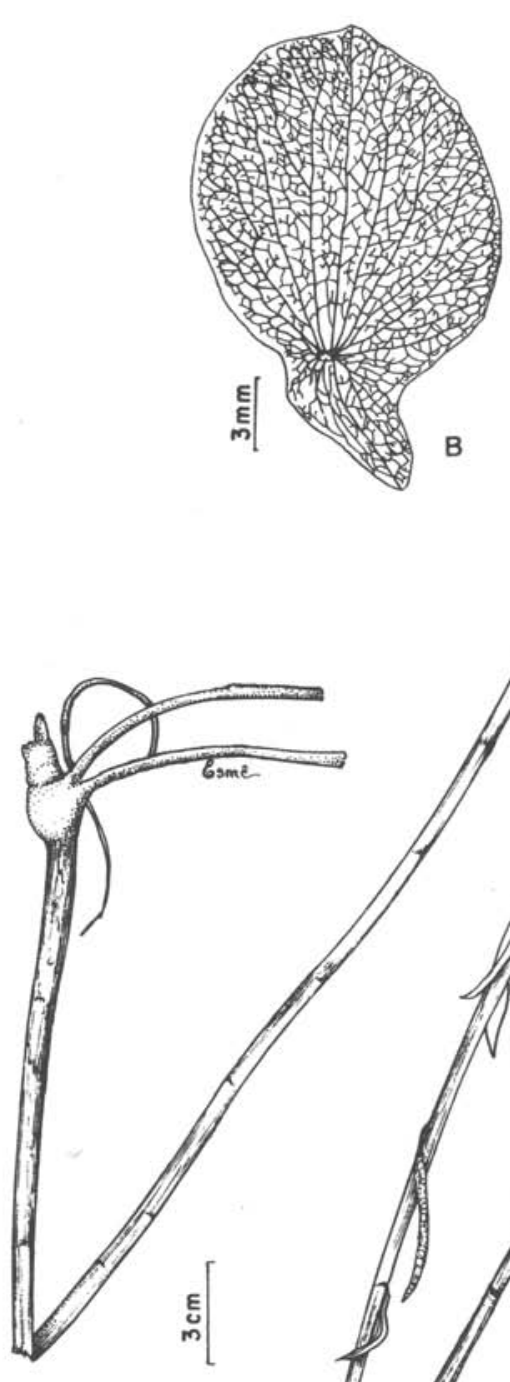
Subarbusto de $30 \mathrm{~cm}$ de altura. Ramos eretos e seríceos. Estípulas 22 × 5-6 mm, ovadas, esparso-seríceas, sem pontuações, com 9-11 nervuras longitudinais, aurícula basal de $6 \mathrm{~mm}$ compr. Folha 2-foliolada; pecíolo das folhas inferiores 14-17 mm compr. e das superiores 11-14 mm compr., esparso-seríceo; peciólulos velutinos; folíolos papiráceos, sem pontuações, venação na face abaxial emersa e imersa na adaxial; folíolos inferiores $15-25 \times 15 \mathrm{~mm}$, elípticos, ápice e base obtusos, esparso seríceos; folíolos superiores $35-50 \times 12 \mathrm{~mm}$, oval-lanceolados, ápice agudo e base aguda a arredondado-assimétrica, esparsamente velutinos. Espigas com raque 10-22 cm compr., velutina a serícea. Bractéolas 20-22 x 8-10 mm, oval-elípticas, esparsoseríceas, densamente pontuadas, com 5-7 nervuras; aurícula basal 3-5 x 3-4 mm. Cálice $3 \mathrm{~mm}$ compr., seríceo e ciliado, não pontuado, 7-nervado. Lomento 5-6articulado, velutino; artículo $2,5 \times 3 \mathrm{~mm}$, com acúleos de $1 \mathrm{~mm}$ compr., recobertos de tricomas eretos, reticulado, sem pontuações. Sementes com hilo circular; carúncula com 2 saliências circulares; embrião reto, submediano; cotilédone circular a obovado, comprimido, não pontuado, 1,5 x 1,5 mm.

Zornia cryptantha, estabelecida por Arechavaleta (1901), foi sinonimizada por Burkart (1939) com Z. latifolia DC., nome ilegítimo por ser um homônimo posterior de Z. latifolia $\mathrm{Sm}$. O nome da espécie, Z. cryptantha, foi restabelecido por Mohlenbrock (1961).

Vanni (1981) sinonimizou Zornia lanata Mohlenbr. com Z. cryptantha e reconheceu ainda 2 variedades: $Z$. cryptantha var. cryptantha e Z. cryptantha var. latibracteata Vanni, com base na forma, indumento e largura das bractéolas e no tamanho dos folíolos superiores. O material examinado não foi identificado em nível varietal, pois apresentou características intermediárias entre estas duas variedades.

Zornia vestita Mohlenbr. é muito próxima de Z. cryptantha, apresentando caracteres diagnósticos muito tênues e até mesmo relativamente sobrepostos, talvez um extremo da variação morfológica de Z. cryptantha. Embora a observação do tipo de Z. vestita, Black 51-11117 (IAN), fortaleça estas considerações, é necessária uma análise mais detalhada da amplitude morfológica das populações destas espécies.

Zornia cryptantha tem caracteres de fácil observação porque apresenta folhas, ramos e bractéolas com indumento denso, folíolos mais largos que os das demais espécies e frutos com acúleos e com indumento.

A distribuição de Zornia cryptantha em São Paulo (Fig. 2) é ampla, ocorrendo desde os cerrados de Pirassununga até os campos de altitude de Itararé. Ocorre ainda em Minas Gerais, Paraná e Rio Grande do Sul e em outros países como Argentina, Bolívia, Colômbia, Paraguai, Uruguai e Venezuela (Mohlenbrock 1961).

Material Examinado: São Paulo: Botucatu, 30/XI/1973, J. Manetti Filho s/n, fl., fr. (BOTU); Botucatu, 19/1/1976, Coleman \& Menezes 27, fl., fr. (SP); Botucatu, 19/XI/ 1976, J.R. Coleman 27, fr. (RB); Botucatu, 27/XI/1979, M.A.M. dos Reis s/n, fl., fr. (BOTU); Campinas, 4/XII/1938, O. Zagatto \& A. Vetorato 3065, fr. (SP); Iperó, 10/ XI/1936, Hoehne \& A. Gehrt, fl., fr. (SP 36752); Itaberá, 7/XII/1966, J. Mattos 14305, 


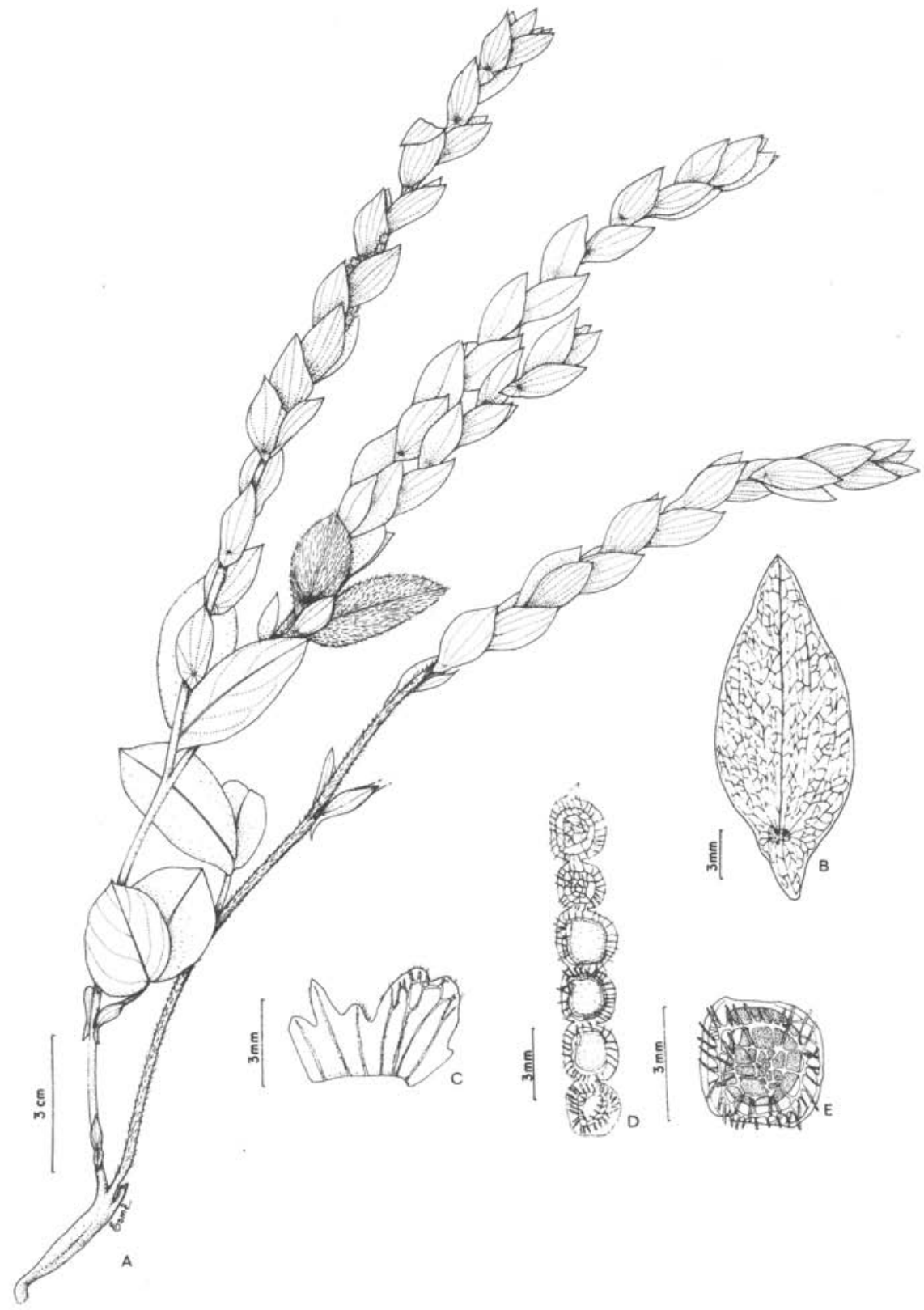

Figura 4. Zornia cryptantha Arechav. A - aspecto geral do ramo (J.L.Mattos 16110 \& N.F. Mattos), B bractéola (Hoehne \& Gehrt SP 36752), C - cálice ( J.L.Mattos 16110 \& N.F. Mattos), D - lomento, E artículo (Hoehne \& Gehrt SP 36752). 
fl., fr. (SP); Itapetininga, 21/XI/1962, J. Mattos 10712 \& H.Bicudo, fl., fr. (SP); Itapetininga, 3/XII/1974, J. Mattos 16110 \& N. Mattos, fl., fr. (SP); Itararé, X/1965, J. Mattos 12853 \& C. Moura, fr. (SP); Itirapina, 28/I/1984, H.F. Leitão Filho et al. 15928 (UEC); Pirassununga, 1/XII/1944, M. Rachid, fr. (SPF 62878); Tatuí, 30/I/1918, F.C. Hoehne 1407, fl., fr. (SP). Rio Grande do Sul: Júlio de Castilhos, 5/XII/1993, J.R. Stehmann 1194 , J.H.A. Dutilh \& A. Sciamarelli, fl. (UEC).

4. Zornia ramboiana Mohlenbr., Webbia 16 (1): 90. 1961.

Figura 2 e Figura 5 A-E

Subarbusto com cerca de $15 \mathrm{~cm}$ de altura. Ramos eretos, velutinos. Estípulas $13 \mathrm{x}$ 1-2 mm, oval-lanceoladas, pontuadas, seríceas, com 7 nervuras longitudinais; aurícula basal de 4-5 x $1 \mathrm{~mm}$. Folha 2-foliolada; pecíolo dos folíolos inferiores 12-17 mm compr., esparso-seríceo e dos superiores 9-12 mm compr., densamente velutino; folíolos de venação broquidódroma e reticulada em ordens superiores, emersa na face abaxial e imersas na adaxial; folíolos inferiores 12-17 × 7-12 mm, obovados, ápice e base obtusos, esparso-seríceos, papiráceos, sem pontuações; folíolos superiores 25-30 x 8-12 mm, lanceolados, ápice e base agudos, seríceos, pontuados na face adaxial. Espigas com raque de 5-7 cm compr., velutinas. Bractéolas 12-14 x 4-5 mm, oval-lanceoladas; aurícula basal 2-5 mm compr., seríceas no limbo e ciliadas, esparso-pontuadas, com 7 nervuras. Cálice $3 \mathrm{~mm}$ compr., velutino nas margens e nervuras do lacínio carenal, 22nervado. Lomento 6-articulado, artículos 1,5-2 mm compr., seríceo-vilosos, sem acúleos, reticulados, sem pontuação, dispostos em ângulos, formando ziguezague. Sementes com hilo circular; carúncula com 2 saliências circulares; embrião reto, submediano; cotilédones $1,5 \times 1,5 \mathrm{~mm}$, obovados, comprimidos, lisos, não pontuados.

Zornia ramboiana foi estabelecida por Mohlenbrock (1961) com base em caracteres como cálice com 15 a 22 nervuras e fruto sem acúleos e com indumento denso. Z. hebecarpa é uma espécie próxima, que também possui frutos sem acúleos, possui folhas obtusas, com muitas pontuações e bractéolas com aurículas divididas, caracteres que a diferenciam de $Z$. ramboiana, associados a sua distribuição geográfica que é restrita a Minas Gerais.

Uma particularidade a ser destacada dos frutos de Z. ramboiana é que seus artículos formam ângulos opostos e alternados entre si, em ziguezague, apresentando reticulação escura, além de serem densamente seríceos.

Zornia ramboiana foi encontrada apenas nos municípios de São Paulo e Itararé (Fig. 2), estendendo-se ao Sul pelos outros Estados até o Rio Grande do Sul (Mohlenbrock 1961).

Material Examinado: São Paulo: Itararé, 10/XII/1966,J. Mattos 14916 \& N.F. Mattos, fl., fr. (SP); São Paulo, X/1914, F.C. Hoehne 7273, fl., fr. (SP); São Paulo, 19/X/1918, F.C. Hoehne, fl., fr. (SP 4148); São Paulo, 4/I/1934, F.C. Hoehne, fl., fr. (SP 32076); São Paulo, 2/XII/1941, W. Hoehne, fl., fr. (SPF 10857). 


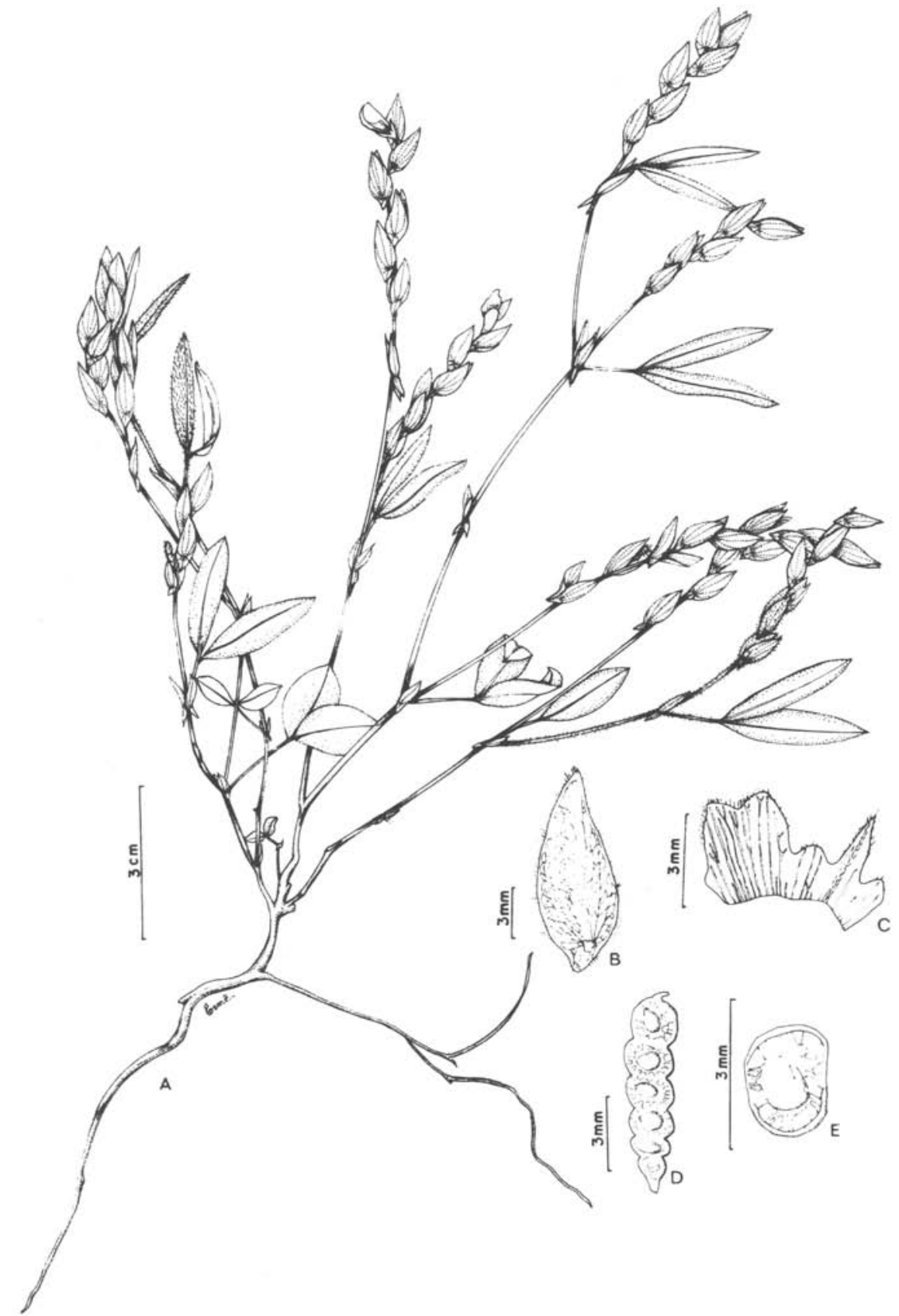

Figura 5. Zornia ramboiana Mohlenbr. A - aspecto geral do ramo, B - bractéola, C - cálice (Hoehne SP 32076), D - lomento, E - artículo (Hoehne SP 32076). 
5. Zornia glabra Desv., Mem. Soc. Linn. Par. 4: 325. 1826.

Figura 2 e Figura 6 A-E

Subarbusto $15-45 \mathrm{~cm}$ altura. Ramos eretos, glabros a esparso-estrigosos, pontuados. Estípulas 13-20 x 1-3 mm, lanceoladas, ápice sub-cuspidado, pontuadas, glabras, 5-6 nervuras; aurícula basal 6-9 x 1-2 mm. Folhas 2-folioladas; pecíolo de 14-20 mm compr., glabro a esparso-estrigoso; peciólulos 1-2 mm compr.; folíolos de venação imersa em ambas as faces, ápice agudo e mucronado, base levemente assimétrica, pontuados, glabros; folíolos inferiores 15-60 × 2-8 mm, obovados a ovais; superiores 15-25 x 3-4 mm, oblanceolados. Espigas laxas com raque de $10-15 \mathrm{~cm}$ compr., glabra a estrigosa. Bractéolas 15-19 x 5-7 mm, ovais, glabras a esparsoestrigosas no limbo e ciliadas, pontuadas, com 5-7 nervuras longitudinais; aurícula basal oval-lanceolada, 2-5 x 1-2 mm. Cálice $4 \mathrm{~mm}$ compr., glabro no limbo e longociliado, 9-nervado. Lomento 5-7-articulado, glabro a esparso-seríceo, artículos $2 \times 2$ mm, reticulados, acúleos 1-2 mm compr., seríceos, sem pontuações. Sementes com hilo circular; rafe lanceolada; carúncula ausente; embrião submediano; cotilédone 2,2 x 1,8 mm, retangular, não pontuado.

Para Mohlenbrock (1961), o conceito de Zornia glabra engloba duas das variedades reconhecidas por Bentham (1859), Z. diphylla var. reticulata Benth. e Z. diphylla var. elatior Benth., a última incluindo ainda Z. perforata Vogel. Este procedimento ressalta a nítida continuidade dos caracteres morfológicos existente entre as variedades de Z. diphylla s. ampl. (Tab. 1).

Zornia glabra é uma espécie próxima de Z. reticulata, porém as bractéolas de Z. glabra são mais glabras e mais ovais, as aurículas mais estreitas e os frutos com acúleos maiores e mais escuros.

Zornia glabra é citada pela primeira vez para o Estado de São Paulo. Ocorre desde o litoral até o interior, em restingas e cerrados (Fig. 2). Citada para Bahia, Rio de Janeiro, Rio Grande do Sul, Suriname e Peru (Mohlenbrock 1961). Segundo Mohlenbrock (l.c.), Z. glabra parece ser mais abundante ao longo dos cursos d'água.

Material Examinado: São Paulo: Bertioga, 7/VII/1983, M. Kirizawa et al. 1001, fl., fr. (SP); Botucatu, 3/X/1973, A.P. Brioschi 1710, fl. (BOTU); Botucatu, 15/XI/1973, A.M. Oliveira 10, fl. (BOTU); Botucatu, 19/X/1974, L.M. Paleari 15, fl. (BOTU); Botucatu, 19/X/1974, L. Mori 4280, fl. (BOTU); Botucatu, 26/X/1974, M.E. Gomes 4281, fl. (BOTU); Botucatu, 19/X/1974, E. Trevizan 4279, fl., fr. (BOTU); Campinas, 2/II/1984, G.M. Felippe 15762, fr. (UEC); Itapetininga, 3/XII/1974, J. Mattos 16131 \& N. Mattos, fl., fr. (SP); Itararé, X/1965, J. Mattos 12890 \& C. Moura, fl., fr. (SP); Itirapina, 30/XI/1961, G. Eiten \& Freitas Campos 3401, fr. (US); Itirapina, 11/IV/ 1962, I.M. Válio 227, fl., fr. (SP); Itirapina, 16/XII/1965, J.E. Paula 157, fr. (SP); Itirapina, 19/XII/1984, O. Cesar 379, fl. (HRCB); Itirapina, 18/I/1985, O. Cesar 387, fl., fr. (HRCB); Mogi Guaçu, 14/X/1980, W. Mantovani 1099, fr. (SP); Mogi Guaçu, 15/X/1980, W. Mantovani 1149, fr. (SP); Mogi-Mirim, 19/X/1983, T. Nucci et al. 15501, fl., fr. (UEC); Pirassununga, 24/XI/1940, s/col., fl., fr. (SPF 62880); Pirassu- 


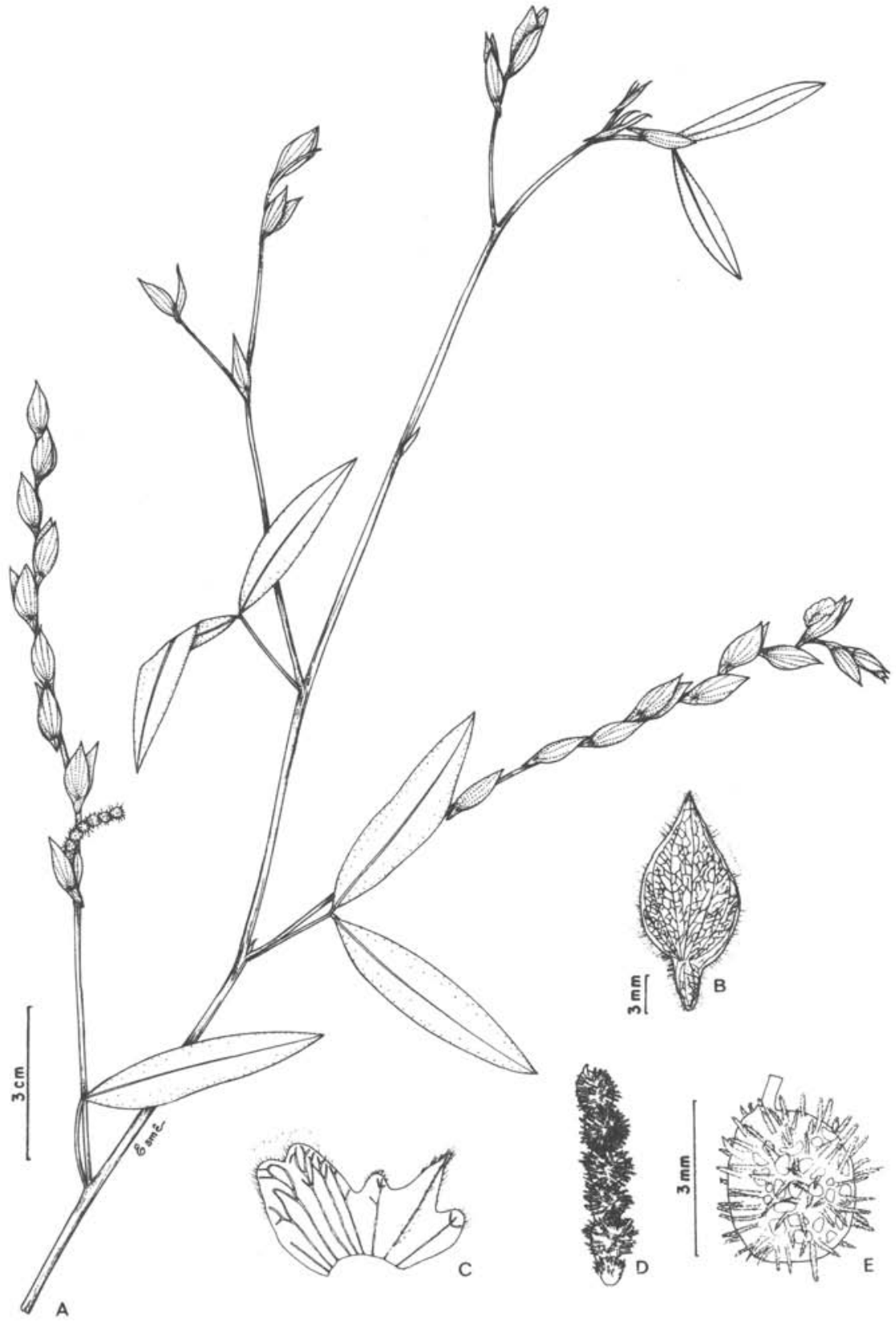

Figura 6. Zornia glabra Desv. A - aspecto geral do ramo (M. Kirizawa et al. 1001), B - bractéola (SPF 62880), C - cálice (G. Eiten \& J.M. Freitas Campos 3401), D - lomento, E - artículo (SPF 62880). 
nunga, 11/XI/1978,M.M.R. de Meo \& S.L. Jung 83, fl., fr. (SP); São José dos Campos, 24/XI/1961, I. Mimura 106, fl., fr. (SP, US); São José dos Campos, 30/XII/1961, I. Mimura 186, fl., fr. (SP); São José dos Campos, 23/XI/1967, I. Mimura 640, fl., fr. (SP); São Simão, 22/V/1957, M. Kuhlmann 4141, fr. (SP).

\section{Zornia reticulata Sm., Cycl. 39: 2. 1819.}

Figura 2 e Figura 7 A-E

Subarbusto 30-100 cm altura. Ramos eretos e prostrados, glabros a vilosos. Estípulas 13-21 x 2-5 mm, lanceoladas, glabras a tomentosas, não pontuadas, com 4 a 6 nervuras longitudinais; aurícula basal 6-10 mm compr. Folha 2-foliolada; pecíolo e peciólulo tomentosos, de 5-18 mm compr. e 1-2 mm compr., respectivamente; folíolos pontuados, papiráceos, glabros a tomentosos, venação emersa na face inferior e na superior imersa; folíolos inferiores 4-40 × 4-20 mm, orbiculados a elípticos, ápice e base obtusos; folíolos superiores 25-55 × 4-11 mm, oblongo-lanceolados, ápice agudo e base obtusa. Espigas com raque de 10-18 cm compr., glabra a vilosa. Bractéolas 11 $20 \times 3-5 \mathrm{~mm}$, glabras a tomentosas, oblongo-lanceoladas, pontuadas, com 5-6 nervuras; aurícula basal 3-6 mm compr., triangular. Cálice $4 \mathrm{~mm}$ compr., esparso-velutino e ciliado, 7-nervado. Lomento 6-8-articulado; artículo $2 \times 2 \mathrm{~mm}$, acúleos raramente presentes de 0,1-1 mm compr., tomentosos, obscuramente reticulado, não pontuado. Sementes com hilo circular; rafe e carúncula ausentes; embrião reto, submediano; cotilédone $1,5 \times 1,5 \mathrm{~mm}$, quadrangular, não pontuado.

A espécie apresenta grande variação morfológica e conseqüentemente várias categorias infra-específicas foram estabelecidas por diversos botânicos. Vogel (1838) descreveu 3 variedades (Zornia reticulata var. glabra, Z. reticulata var. punctata e Z. reticulata var. elongata), enquanto que Bentham (1859) reconheceu apenas 2 destas variedades (Z. reticulata var. glabra e Z. reticulata var. punctata). Chodat \& Hassler (1904) descreveram mais 2 variedades ( $Z$. reticulata var. paraguariensis e $Z$. reticulata var. rupestris) e 2 formas (Z. reticulata f. ciliata e Z. reticulata f. intermedia) e Malme (1931) 2 subespécies (Z. reticulata ssp. cuyabensis e Z. reticulata ssp. subperforata). Mohlenbrock (1961) considerou cerca de 15 taxa como sinônimos de $Z$. reticulata, incluindo os citados. As diferenças entre $Z$. reticulata e as espécies próximas não foram bem descritas por Mohlenbrock (l.c.).

As bractéolas de Zornia reticulata são caracteristicamente oblongo-lanceoladas, o lomento raramente possui acúleos, mas quando os tem estes são muito curtos, de 0,2-0,5 mm de compr. e um ou dois de seus artículos ficam expostos para fora das bractéolas. O hábito é o mais prostrado e laxo quando comparado ao das espécies analisadas, com poucos ramos longos.

Zornia reticulata é a espécie de mais ampla distribuição pelo Estado, estando presente em quase todas as regiões (Fig. 2), dividindo o espaço com todas as outras espécies, inclusive com Z. virgata. Está amplamente dispersa pelo continente americano, desde o Sul dos Estados Unidos (Texas e Arizona), estendendo-se pelas Antilhas e América Central e do Sul, até os limites próximos ao trópico de Capricórnio no 


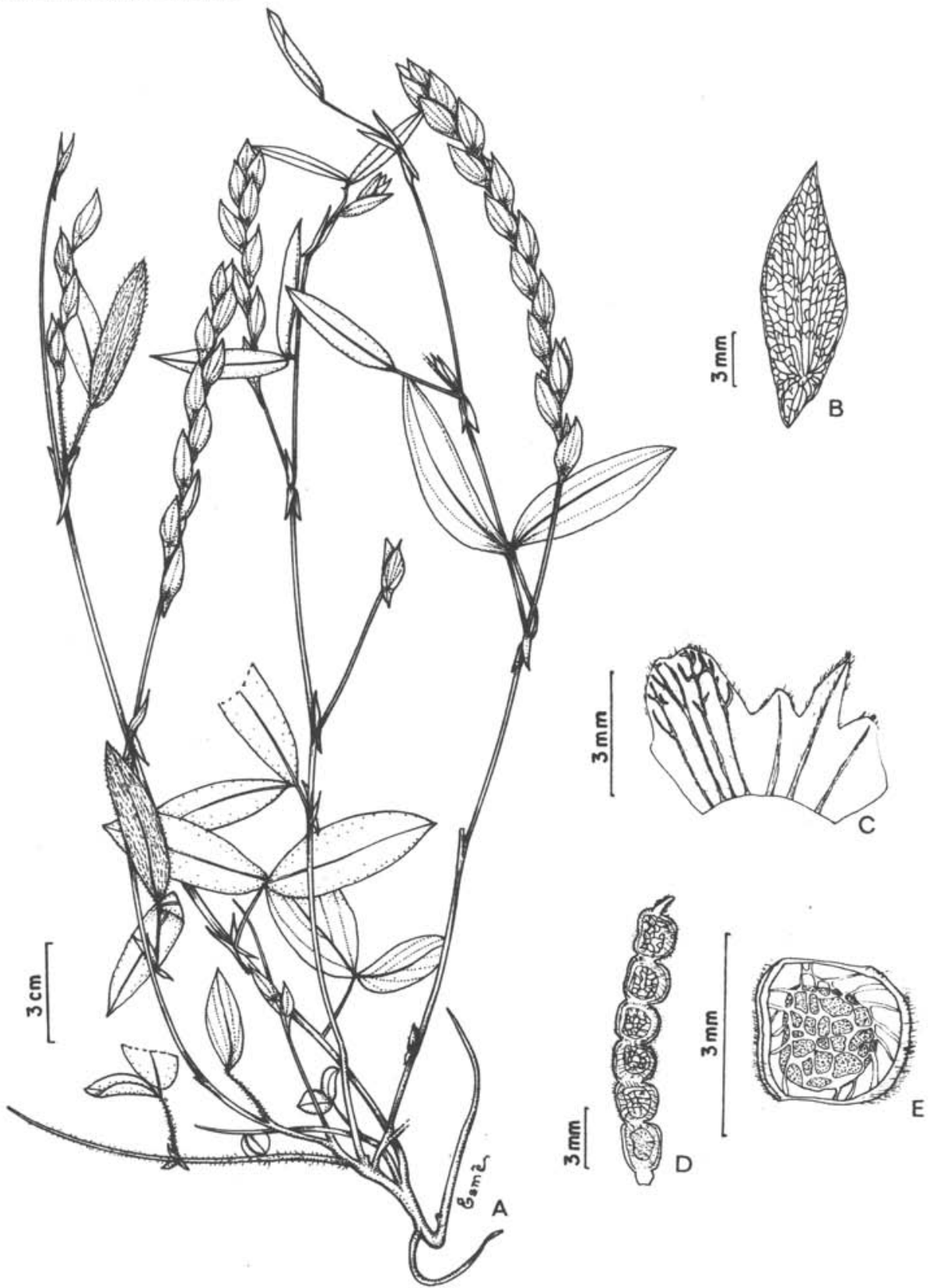

Figura 7. Zornia reticulata Sm. A - aspecto geral do ramo, B - bractéola (Mimura 235), C - cálice (Mimura 235), D - lomento, E - artículo (Mantovani 1392). 
Paraguai e São Paulo (Mohlenbrock 1961). No presente estudo foi constatada sua ocorrência também em localidades mais ao Sul, nos Estados de Santa Catarina e do Rio Grande do Sul.

Material Examinado: São Paulo: Avaré, 15/III/1967,J. Mattos 14502 \& N. F. Mattos, fl., fr. (SP); Botucatu, 3/XI/1971, E. Tonioli 42, fl., fr. (BOTU); Botucatu, 24/X/1972, R.A. Rodella 3, fl. (BOTU); Botucatu, 24/X/1972, J. Ishida s/n, fl., fr. (BOTU); Botucatu, 24/ X/1972, I. Takaki 3, fl. (BOTU); Botucatu, 24/X/1972, E. Melotto 3, fl., fr. (BOTU); Botucatu, 24/X/1972,F. Costa 6, fl. (BOTU); Botucatu, 24/X/1972,J.V. Gonzales 3, fl., fr. (BOTU); Botucatu, 6/XI/1972, W. Endo 26 fl., fr. (BOTU); Botucatu, 9/XI/1972, M.V. Guerra 19, fl., fr. (BOTU); Botucatu, 9/XI/1972, C.A.N. Seabra 32, fl. (BOTU); Botucatu, 10/XI/1972, I.C. Périco 15, fl., fr. (BOTU); Botucatu, 15/IX/1974, M.Ap. Manetti 5, fl. (BOTU); Botucatu, 2/XI/1974, M. Marculin 17, fl. (BOTU); Botucatu, 19/ $\mathrm{I} / 1976$, J. R. Coleman \& E. M. Menezes 22, fl. (SP); Botucatu, 5/XI/1977, R. Ishikawa 15, fl. (BOTU); Botucatu, 22/II/1980, Noronha 65, fl., fr. (HRCB); Botucatu, 16/X/ 1980, M.W.M. Huysmnas 17, fl. (BOTU); Botucatu, 26/I/1982, L.M.L. Duarte et al. s/n, fr. (BOTU); Botucatu, 28/1//1986, E.O. Ono s/n, fl., fr. (BOTU); Botucatu, 11/1II/1986, Bicudo \& Campos 733, fl., fr. (SP); Botucatu, 25/II//1986, L. R. H. Bicudo et al. s/n, fl., fr. (BOTU); Botucatu, 25/III/1986, Bicudo \& Campos 824, fl. (SP); Botucatu, 8/XI/ 1993, A. Sciamarelli et al. 28958, fr. (UEC); Botucatu, s/data, F. C. Hoehne 13310, fl., fr. (SP); Brotas, 28/VI/1976, T. C. Ferreira et al. IZ-654, fl., fr. (UEC); Campinas, 7/XI/ 1935, W.G. Howk 39, fl., fr. (US paratipo de Z vestita Mohlenbr.); Campinas, 16/XI/ 1935, W.G. Howk 50, fl., fr. (US paratipo de Z. vestita Mohlenbr.); Campinas, 28/II/ 1936, J. Santoro 396, fl. (US); Campinas, 4/X/1936, J. Santoro 732, fl., fr. (ESA, US); Campinas, 3/X/1938, A.P. Viegas s/n, fl. (HRCB); Campinas, II/1953,D.M. Dedecca s/ n, fr. (HRCB); Campinas, 3/II/1956, A. B. Joly 5768, fl., fr. (SP); Campinas, 23/III/1970, O. Bacchi 20965, fr. (IAC); Campinas, X/1970, H.F. Leitão Filho 21968, fl., fr. (IAC); Campinas, 12/I/1971, A.D. Almeida 21376, fl., fr. (IAC); Campinas, 13/X/1971, E. Lopes 219, fl., fr. (IAC); Campinas, X/1972, H.F. Leitão Filho 23037, fl., fr. (IAC); Campinas, 1/XI/1992, A. Sciamarelli 697, fl., fr. (UEC); Campinas, 20/XI/1992, A. Sciamarelli 696, fl., fr. (UEC); Campinas, 29/X/1993, A. Sciamarelli 699 e A. Sciamarelli 700, fl., fr. (UEC); Capão Bonito, 19/X/1966, J. Mattos 13988, fl., fr. (SP); Capão Bonito, 19/X/1966, J. Mattos 13941, fl. (SP); Capão Bonito, 19/X/1966, J. Mattos 13988, fl. (HB); Cerqueira Cesar, 9/XI/1993, A. Sciamarelli et al. 28980, fl., fr. (UEC); Corumbataí, 7/V/1961, H. do Amaral s/n, fl., fr. (HRCB); Indaiatuba, 5/I/1954, A.S. Grottas/n, fr. (SPF 15224); Ipanema, 16/I/1962, J. Feliciano 4, fl., fr. (SP); Itapetininga, 3/XI/1946, J.I. Lima 58109, fl. (RB); Itapetininga, 27/XII/1960, G.M. Felippe 16 e 16A, fl., fr. (SP,RB); Itapeva, I/1958, J. Vidal 131532, fl. (R); Itaquaquecetuba, 20/X/1936, Hoehne \& A. Gehrt 36543 e 36546, fl., fr. (SP); Itatiba, 20/1I/1971, H. F. Leitão Filho 1122, fr. (IAC); Itararé, 29/X/1965, J. Mattos 14988 \& C. Moura, fl. (SP); Itararé, X/ 1965, J. Mattos \& N.F. Mattos 1292I, fl., fr. (SP); Itirapina, 30/XI/1961, G. Eiten \& J.M.F. Campos 340I, fl. (SP); Itirapina, 11/V/1962, I.M. Válio 227, fl., fr. (RB); Itirapina, 19/XII/1984, O. Cesar 515, fl. (HRCB); Jundiaí, 3/II/1907, A. Usteri 74, fr. 
(SP); Limeira, 12/II/1949, J.I. Lima 69958, fr. (RB); Mineiros do Tietê, 6/VIII/1971, H.F. Leitão Filho 1254, fl., fr. (IAC); Mogi das Cruzes, 20/IV/1889, Schwacke 38093, fr. (RB); Mogi das Cruzes, 29/XII/1966, J. Mattos \& N. F. Mattos 14275, fl., fr. (SP); Mogi Guaçu, 16/XI/1960, J.R. Mattos \& N. Mattos 8441, fl., fr. (SP, US); Mogi Guaçu, 14/IV/1961, J.R. Mattos \& N.F. Mattos 2589 e 2590, fr. (SP); Mogi Guaçu, 13/XII/ 1962, G.Eiten \& L.Eiten 5054, fl., fr. (SP, US); Mogi Guaçu, 6/IL/1980, W. Mantovani 423, fl. (SP); Mogi Guaçu, 15/X/1980, W. Mantovani 1150, fl. (SP); Mogi Guaçu, s/ data, W. Mantovani 1392, fr. (SP); Mogi Guaçu, 16/X/1980, W. Mantovani \& M. Suguyama 1217, fl. (SP); Mogi Guaçu, 19/XI/1980, A. Custódio Filho 480,fl. (SP); Mogi Guaçu, 20/XI/1980, G. Eiten \& L. Eiten 1392, fl., fr. (SP); Mogi Guaçu, s/data, G. Eiten \& L. Eiten s/n, fr. (SP, US); Mogi Guaçu, 27/I/1981, G. Eiten \& L. Eiten 1620, fl., fr. (SP); Mogi Guaçu, s/ data, W. Mantovani 1392, fr. (SP); Pirassununga, 1943, M. Rachid, fr. (SPF 62879); Pirassununga, 3/XII/1944, M. Rachid, fl., fr. (SPF 62877); Pirassununga, 21/XI/1982, M. Kirizawa 877, fl. (SP); Porto Ferreira, 6/1I/1969, E. Lopes 95, fl. (IAC); Pinhal, 13/XI/1947, E. Kuehn \& M. Kuhlmann 1511, fl., fr. (SP); São Carlos, 2/XII/1961, G. Eiten \& J.M.F. Campos 3494, fl., fr. (SP); São Paulo, 1/1V/1906, A. Usteri 13309, fr. (SP); São Paulo, 6/III/1908, Luederwaldt 13316, fl., fr. (SP); São Paulo, XI/1914, A.C. Brade 7274, fl., fr. (SP); São Paulo, 13/V/1917, F.C. Hoehne 131, fl., fr. (SP); São Paulo, 21/III/1930, A. Gehrt 25253, fl., fr. (SP); São Paulo, 10/XII/1932, W. Hoehne s/n, fl., fr. (SPF 10332, SP e US); São Paulo, 28/II/1933, W. Hoehne s/n, fl, fr (SPF 10334); São Paulo, 31/XII/1939, B. Pickel 42249, fl., fr. (SP); São Paulo, 29/VII/ 1948, W. Hoehne, fl. (SPF 12221); São Paulo, 23/IV/1957, M. Kuhlmann \& S. Jimbo 154570, fr. (SP); São Paulo, 7/IV/1960, G. Eiten \& L. Eiten 1827, fl., fr. (SP, US); São Paulo, 14/XII/1966, T. Sendulsky 508, fr. (SP); São Paulo, 4/L/1968, K.G. Hell 32227, fl., fr. (SPF); São Paulo, 1980, s/col. s/n, fl., fr. (SPF); São Paulo, 2/XII/1980, M. Mangels s/n, fl., fr. (SPF); São Paulo, s/data, T. de Bacharelado de 1980, fl., fr. (SPF 16782); São Paulo, 5/IV/1990, Santos \& Takahashi 6, fl., fr. (SPF); São Carlos, 28/I/ 1961, G. Eiten \& L. Eiten 2531, fr. (SP); São Carlos, 2/XII/1961, G. Eiten \& J.M. Campos 3494, fl., fr. (SP, US, F); São José dos Campos, 14/XI/1961, I. Mimura 83, fl. (SP, US); São José dos Campos, 20/XII/1961, I. Mimura 165, (SP, US); São José dos Campos, 15/I/1962, I. Mimura 189, fl., fr. (SP,US); São José dos Campos, 27/I/1962, I. Mimura 215, fl. (SP, US); São José dos Campos, 30/I/1962, I. Mimura 235, fl., fr. (SP, US); São José dos Campos, 15/IX/1970, H.F. Leitão Filho 1030, fr. (IAC); São José dos Campos, 1/XII/1976, F.S. Cavalcante 15, fl., fr. (SP); São Sebastião, 10/XI/1976, P. Gibbs et al. 305 fl., fr. (UEC); Valinhos, 14/IV/1964, D.O. Norris 156, fl., fr. (SP); Votorantin, 12/I/1984, V.F. Ferreira 3198, fl. (GUA).

7. Zornia latifolia Sm., Cycl. 39: 4. 1819.

Figura 2 e Figura 8 A-E

Subarbusto prostrado, $30 \mathrm{~cm}$ altura. Ramos laxos, decumbentes, esparso-seríceos. Estípulas 5-7-(13) x 2-4 mm, oval-lanceoladas; aurícula basal de $1 \mathrm{~mm}$ compr., glabras a seríceas, com 6 nervuras longitudinais, pontuadas. Folha 2-folioladas, 


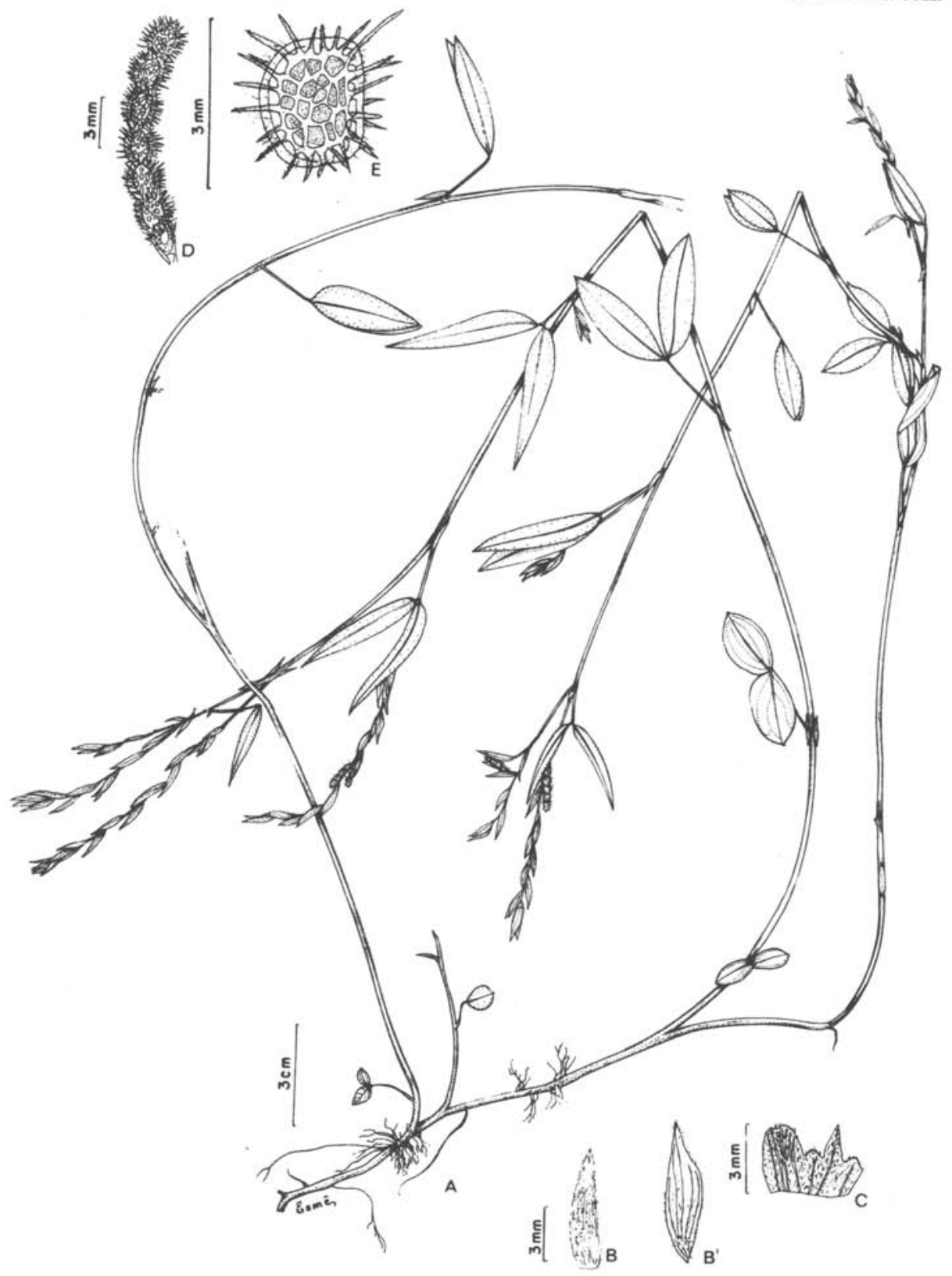

Figura 8. Zornia latifolia Sm. A - aspecto geral do ramo (G. Eiten \& L. Eiten 2654). B - bractéola (G. Eiten \& L. Eiten 2602), B' - bractéola (G. Eiten \& L. Eiten 2329), C - cálice (G. Eiten \& L. Eiten 2602), D - lomento, E - artículo (G. Eiten \& L. Eiten 2602). 
pecíolo das folhas inferiores e superiores de 10-24 mm compr.; peciólulo 1-2 mm compr., glabro a esparso-seríceo; folíolos com ápice mucronado e base obtusa, glabros a seríceos, venação broquidódroma e reticulada em ordens superiores, pontuados, papiráceos; folíolos inferiores 7-20 × 3-10 mm, oval-elípticos, nervuras emersas em ambas as faces; folíolos superiores 10-50 × 2-17 mm, elíptico-lanceolados, nervuras emersas na face inferior e imersas na superior. Espigas com raque de 30-63 mm compr., serícea. Bractéolas 5-11 x 1-3 mm, estreito-elípticas, seríceas, com 3-6 nervuras longitudinais, pontuadas; aurícula basal geralmente ausente ou até $1 \mathrm{~mm}$ compr. Cálice $3 \mathrm{~mm}$ compr., seríceo no limbo e velutino nas nervuras, 7-nervado. Lomento 5-7-articulado; artículo seríceo, 2-3 × $2 \mathrm{~mm}$, acúleos $1 \mathrm{~mm}$ compr., reticulado, não pontuado. Sementes com protuberâncias na testa, hilo circular; embrião reto, submediano; cotilédones $1,8 \times 0,5 \mathrm{~mm}$, retangulares, não pontuados.

Mohlenbrock (1961) corrigiu o nome desta espécie, reconhecendo que o basiônimo estabelecido por Smith (1819) era anterior ao de seu homônimo, proposto por De Candolle (1825), este último agora identificado com Zornia cryptantha. Bentham (1859) considerou Z. latifolia DC. como idêntica a Z. ovata Vogel, a qual foi considerada por Mohlenbrock (l.c.) sinônimo de Z. latifolia Sm.

Zornia latifolia é distinguível por apresentar uma bractéola pequena, muito estreita e quase linear, com uma aurícula basal inconspícua (menor que $1 \mathrm{~mm}$ de compr.) e fruto claramente exposto com acúleos grandes de 1-1,5mm de compr., reticulado e com artículos também grandes, de $2 \times 2 \mathrm{~mm}$. Difere de Z. gemella pelas bractéolas e pelo tamanho dos acúleos e dos artículos.

A sua distribuição em São Paulo é bastante ampla, indo desde as restingas no litoral até campos de altitude e cerrados no Norte e Noroeste do Estado (Fig. 2). É a única espécie de Zornia sec. Anisophylla que ocorre no extremo Oeste de São Paulo, em longitudes superiores a $50^{\circ}$. Com relação à sua distribuição global, verifica-se que Z. latifolia está amplamente dispersa pela América do Sul, da Venezuela e Colômbia até Argentina e Uruguai, com exceção da região amazônica e andina (Mohlenbrock 1961).

Material Examinado: São Paulo: Araçatuba, 24/XI/1993, A. Sciamarelli et al. 29121, bt. (UEC); Avaré, 15/III/1967,J. Mattos 14503 \& N. F. Mattos, fl., fr. (SP); Cam-pinas, $12 /$ IV/1964,D.O. Norris 143, fl., fr. (SP); Campinas, 23/III/1970, O. Bacchi s/n, fl. (IAC); Cananéia, 6/IV/1978, M. Goes 62, fl., fr. (SP); Caraguatatuba, 20/V/1961, G. Eiten \& L. Eiten 2794, fl., fr. (SP, US, F); Casa Branca, VII/1993, A. Sartori 31048, fl., fr. (UEC); Corumbataí, 8/III/1983, M.J.O. Campos 86, fr. (HRCB); Corumbataí, 10/IV/1984, L. Cordeiro 4, fl., fr. (HRCB); Corumbataí, 16/IV/1950, W. Hoehne, fr. (SPF 12707, F); Ilha do Cardoso, 11/V/1962, F. Torgo 16194, fl., fr. (HB); Itirapina, 29/IV/1923, G. Gehrt 8330, fl., fr. (SP); Matão, 18/I/1963, C. Moura 112, fr. (SP); Matão, 18/1/1963, C. Moura 113, fl., fr. (SP); Matão, 26/IV/1964, D.O. Morris 186, fr. (SP); Matão, 30/IV/ 1964, D.O. Norris 228, fl., fr. (SP); Matão, s/data, H.F. Leitão Filho 1062, fl. (IAC); Mogi Guaçu, 28/IV/1928, C. Duarte \& A. Pacheco 6, fr. (SP); Mogi Guaçu, 19/IV/1960, 
G. Eiten \& L. Eiten 1893, fr. (SP, US); Mogi Guaçu, 21/IV/1960, G. Eiten \& L. Eiten 1917 , fl., fr. (SP); Mogi Guaçu, 22/IV/1960, G. Eiten \& L. Eiten s/n, fl., fr. (US); Mogi Guaçu, 22/IV/1960, G. Eiten \& L. Eiten 2001, fl., fr. (SP, US); Mogi Guaçu, 22/IV/1960, G. Eiten \& L. Eiten 1960, fr. (SP); Mogi Guaçu, 19/VII/1960, G. Eiten \& L. Eiten 2329 , fl., fr. (US); Mogi Guaçu, 16/IV/1961, G. Eiten \& L. Eiten 2602, fr. (SP, US); Mogi Guaçu, 16/IV/1961, G. Eiten \& L. Eiten 2681, fr. (US); Mogi Guaçu, 18/IV/1961, G. Eiten \& L. Eiten 2654, fl., fr. (SP); Mogi Guaçu, 20/IV/1961, G. Eiten \& L. Eiten 2685, fr. (SP); Mogi Guaçu, 3/XI/1976, H.F. Leitão Filho 3393, fl., fr. (UEC, F); Mogi Guaçu, 9/IV/1980,W. Mantovani 634, fl., fr. (SP); Mogi Guaçu, 30/IV/1986, G. de Marini 560, fr. (HRCB); Mogi Guaçu, 7/IV/1993,A.M.G. Azevedo-Tozzi \& A. Sciamarelli 28707, fr. (UEC); Paraguaçu Paulista, 7/II/1965, G. Eiten et al. 5885, fr. (US); Paulo de Faria, 23/ XI/1993, A. Sciamarelli et al. 29111, fl., fr. (UEC); Pedregulho, 10/IV/1920, G. Gehrt 4050, fr. (SP); Peruibe, 12/III/1957, I. Schemtschuschnikowa s/n, fr. (BOTU); Pindorama, 28/XI/1938, O.T. Mendes, fr. (SP 4705); Pindorama, 26/XI/1993, A. Sciamarelli et al. 29145 e 29146, fl., fr. (UEC); Piracicaba, 4/V/1971, Toledo s/n, fl., fr. (ESA); Piracicaba, 4/V/1971, Toledo s/n, fl., fr. (ESA); Santa Cruz do Rio Pardo, 1/II/1987, A. Krapovickas \& C.L. Cristobal 40990, fl., fr. (UEC); São José dos Campos, 28/XI/1961, I. Mimura 125, fl., fr. (US); São José do Rio Preto, 20/V/1965, G. Martins 284, fl., fr. (SP); São José do Rio Preto, 20/XI/1976, M.A. Coleman 4, fr. (SP); São José do Rio Preto, 20/XII/1976, M.A. Coleman 8, fl. (SP); São José do Rio Preto, 22/XI/1978, M.A. Coleman 18, fl. (SP); São José do Rio Preto, 25/XI/1993, A. Sciamarelli et al. 29124, fl., fr. (UEC); São Paulo, 2/III/1961, C.G. Fonseca 28, fl., fr. (US); São Paulo, 13/II/1978, M. Goes 37, fl.,fr. (SP); São Pedro, 12/IV/1976, H.F. Leitão Filho 1883, fl., fr. (UEC); São Sebastião, 27/XII/1971, J. Mattos 15668 \& N.F. Mattos, fr. (SP); São Sebastião, s/ data, Luederwaldt 19024, fl., fr. (SP); São Simão, 22/V/1957, M. Kuhlmann 4140, fr. (SP); São Vicente, 27/III/1955, W. Hoehne, fr. (SPF 15496, F); Tanabi, 25/XI/1993, A. Sciamarelli et al. 29135, 29136 e 29137, fl., fr. (UEC); s/loc., 19/III/1972, E.S. Lopes 239 , fr. (IAC).

8. Zornia curvata Mohlenbr., Webbia 16(1): 132. 1961.

Figura 2 e Figura 9 A-E

Subarbusto $15-40 \mathrm{~cm}$ altura, densamente ramificado. Ramos prostrados ou eretos, glabros a vilosos. Estípulas 6-9 × $2 \mathrm{~mm}$, oval-lanceoladas, glabras, com 5 nervuras longitudinais, pontuadas; aurícula basal de $2 \mathrm{~mm}$ compr. Folha 2-foliolada; pecíolo glabro, nas folhas inferiores $15-18 \mathrm{~mm}$ compr. e nas superiores $7-8 \mathrm{~mm}$ compr.; peciólulo glabro, 1-2 mm compr.; folíolos com base assimétrica, densamente pontuados na face abaxial, papiráceos, glabros; folíolos inferiores 17-37 x 6-9 mm, obovados a oblongo-lanceolados, ápice mucronado, com venação emersa na face abaxial e imersa na adaxial; folíolos superiores 12-22 x 1-3 mm, oblongo-lanceolados, ápice agudo, venação imersa em ambas as faces. Espigas com raque 6-12 cm compr., esparso-serícea. Bractéolas 7-8 × 2-3 mm, oval-lanceoladas, pontuadas, glabras a pubérulas, com 4-5 nervuras longitudinais; aurícula basal de 1-3 mm compr. Cálice 5 


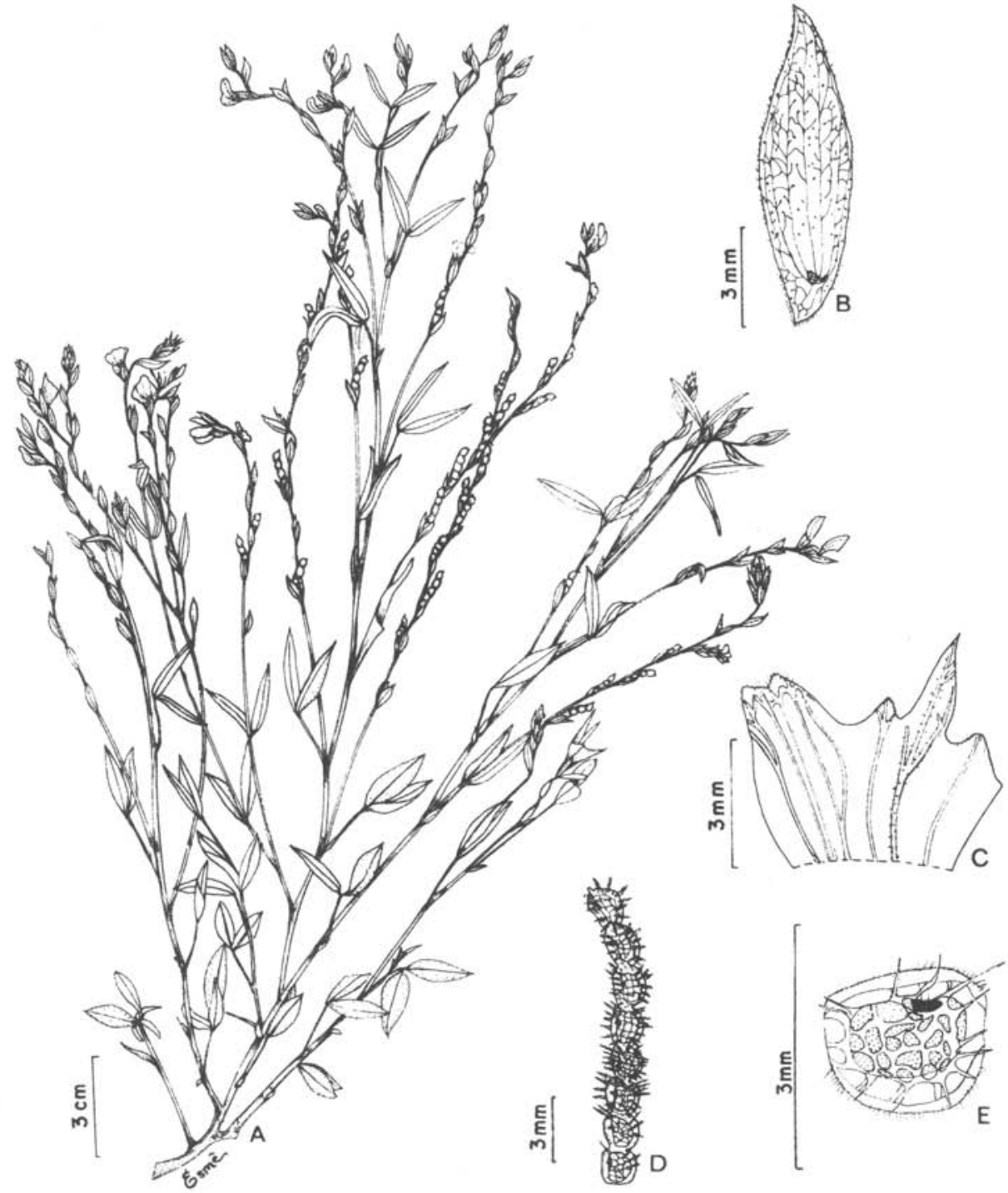

Figura 9. Zornia curvata Mohlenbr. A - aspecto geral do ramo (Hashimoto 75), B - bractéola, C - cálice (Norris I52), D - lomento (Hashimoto 75), E-artículo (W.Hoehne 323I). 
mm compr., seríceo nas margens e nervuras, 8-nervado. Lomento curvo, 6-8-articulado; artículo pubérulo-seríceo, reticulado, não pontuado, $2,0 \times 2,0 \mathrm{~mm}$, acúleos $0,8 \mathrm{~mm}$ compr., seríceos. Sementes com hilo circular; carúncula com 2 saliências circulares próximas ao hilo; embrião reto, submediano; cotilédone 2 x 1,5 mm, retangular, não pontuado.

Esta espécie foi estabelecida por Mohlenbrock (1961), utilizando como característica básica os frutos curvos, a ausência de reticulação, além do seu pequeno porte. Estas características a separam de Zornia reticulata, Z. latifolia e Z. gemella, espécies que se confundem muitas vezes com $Z$. curvata.

Sua distribuição pelo Estado se sobrepõe com a de Zornia gemella, ocorrendo da região Sul até a Sudeste (Fig. 2). A espécie apresenta uma disjunção acentuada, pois foi constatada sua ocorrência no Panamá, Colômbia e Venezuela, no Sul do Peru e na costa Atlântica do Brasil (Mohlenbrock 1961).

Material Examinado: São Paulo: Bragança Paulista, 29/VII/1976, P. Gibbs et al. 218 , fr. (UEC); Campinas, V/1918, C. Novaes 283, fl., fr. (SP-paratipo); Campinas, 28/II/1936, J. Santoro 396, fl. (US); Campinas, 28/XI/1938, A.S. Lima, fl., fr. (SP 4400); Campinas, 12/XII/1940, A.P. Viegas \& A.S. Lima, fl., fr. (SP 5915); Campinas, 19/X/1970, H.F. Leitão Filho 1067, fl., fr. (SP); Campinas, 17/XI/1992, A. Sciamarelli 698, fl., fr. (UEC); Campinas, 19/1/1993, A. Sciamarelli 701, fl., fr. (UEC); Campinas, 19/1/1994, A. Sciamarelli 31049, fl. (UEC); Itapetininga, IV/1947, J. Lima 60718, fl., fr. (RB); Itapetininga, 30/IX/1959, S.M. Campos 42, fl., fr. (SP, F); Itapetininga, 27/XII/1960, I.M. Válio 222, fl., fr. (SP); Itu, 20/I/1970, H.F. Leitão Filho 912, fl., fr. (IAC); Mogi Guaçu, 23/II/1967, J. Mattos 14492, fl., fr. (SP); Santo Amaro, I/1941, I. Hanff 78, fl. (SP); São Paulo, 21///1906, A. Usteri, fr. (SP 13319); São Paulo, 11/III/1906, Usteri, fr. (SP 13315); São Paulo, XI/1906 , Luederwaldt, fl. (SP 13312); São Paulo, 28/1/1912, A.C. Brade, fl., fr. (SP 5644); São Paulo, X/1914, A.C. Brade, fl., fr. (SP 7272); São Paulo, 2/V/1917, F.C. Hoehne, fl., fr. (SP 8); São Paulo, 12/II/1930, F.C. Hoehne, fl., fr. (SP 25199); São Paulo, 18/II/1930, F.C. Hoehne, fl., fr. (SP 25209); São Paulo, 11/III/ 1930,A. Gehrt, fl., fr. (SP 25234); São Paulo, 13///1933, W. Hoehne, fl., fr. (SPF 10333); São Paulo, 28/II/1933, W. Hoehne, fr. (SPF 10353); São Paulo, 9/III/1939, G. Hashimoto 75, fl., fr. (SP); São Paulo, 31/1/1941, B. Pickel 5154, fl., fr. (SP); São Paulo, 2/XII/ 1941, B. Pickel s/n, fr. (SPF); São Paulo, 2/XII/1941, W. Hoehne s/n, fl., fr. (SPF 13231, US, F); São Paulo, 1/II/1946, W. Hoehne fl., fr. (SPF 3230, F); São Paulo, 5/IV/1990, Santos \& Takahashi 26, fl. (SPF); São Paulo, 12/IV/1990, Gregório \& Chris 50, fr. (SPF); Tatuí, 30/I/1918, F.C. Hoehne, fl., fr. (SP 1406); Valinhos, 14/IV/1964, D.O. Morris 152, 154, 157 e 161, fl., fr. (SP); Votorantin, 3/XI/1983, V.F. Ferreira 3121, fr. (GUA). ); s/loc., 20/I/1971, H.F. Leitão Filho s/n, fr. (IAC).

9. Zornia gemella (Willd.) Vogel, Linnaea 12: 61. 1838.

Hedysarum gemellum Willd., Sp. PL. 5: 1178. 1800.

Figura 2 e Figura 10 A-E 


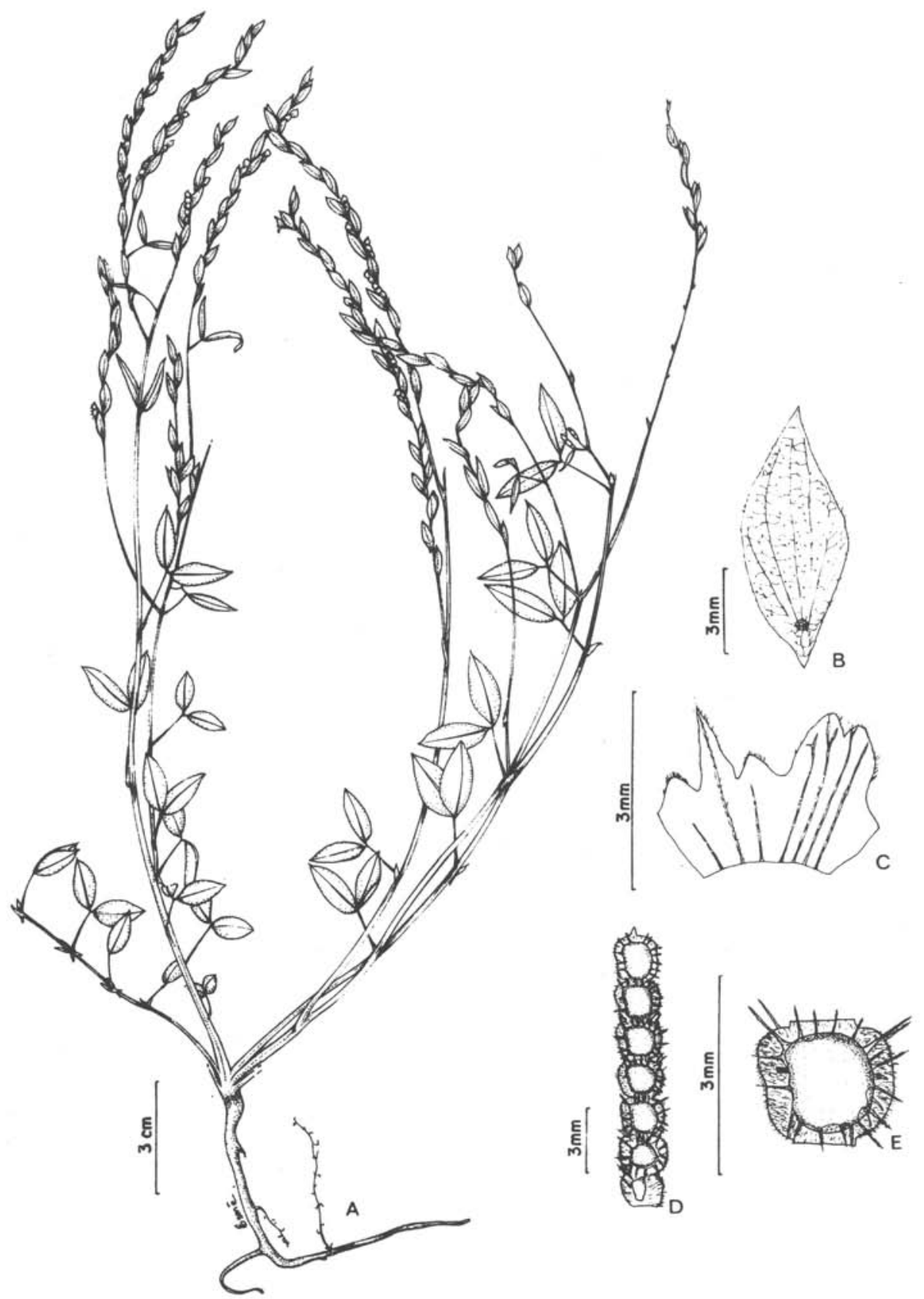

Figura 10. Zornia gemella (Willd. ) Vogel. A - aspecto geral do ramo (M.Kuhlmann 34), B - bractéola (Kuhlmann 34), C - cálice (Kuhlmann 34), D - lomento, E - artículo (Fonseca 28). 
Subarbusto $30 \mathrm{~cm}$ altura. Ramos eretos, glabros a esparso-seríceos. Estípulas 8 10 x 2-3 mm, lanceoladas, 5-6 nervuras longitudinais; aurícula basal 3-4 mm compr. Folha 2-foliolada; folhas inferiores com pecíolo 7-15 mm compr., peciólulo 1-2 mm compr. e superiores com pecíolo 6-8 mm compr., glabro, peciólulo 1-2 mm compr., seríceo; venação dos folíolos imersa em ambas as faces; folíolos inferiores 5-25 × 3$9 \mathrm{~mm}$, ovados, ápice mucronado, base obtusa e assimétrica, esparso-seríceos na face abaxial, glabros na adaxial, pontuados, papiráceos; folíolos superiores 15-17 x 2-3 $\mathrm{mm}$, elíptico-lanceolados ou ovados, ápice agudo, base levemente obtusa, esparsoseríceos, pontuados no limbo e formando uma fileira nas margens, papiráceos. Espigas com raque de 7-15 cm compr., esparso-serícea. Bractéolas 5-10 × 2-4 mm, elípticolanceoladas, limbo glabro e margens setosas, com 6-7 nervuras longitudinais, esparsopontuadas; aurícula basal 1-3 mm compr. Cálice $3 \mathrm{~mm}$ compr., seríceo nas margens e nervuras, 7-nervado. Lomento reto, 4-7-articulado; artículo esparso-seríceo, $2 \times 2 \mathrm{~mm}$, acúleos $0,5 \mathrm{~mm}$ compr., reticulado, pontuado. Sementes com hilo circular; carúncula com 2 saliências circulares; embrião reto, submediano, cotilédones 1,5 x 1,3 mm, quadrangulares, não pontuados.

Zornia gemella tem como características básicas as bractéolas pequenas, de forma que os frutos ficam expostos, os quais são reticulados, com acúleos muito curtos. As diferenças para separá-la de Z. curvata são as bractéolas ovadas e o fruto que não se encurva. Z. gemella apresenta ramos mais prostrados, parecendo um subarbusto menos denso do que Z. curvata e mais do que Z. reticulata, que geralmente apresenta ramos longos. Difere de Z reticulata quanto à morfologia das bractéolas, que são sempre menores, além da já referida exposição dos frutos que em $Z$. reticulata no máximo de 1 ou 2 artículos são expostos.

Zornia gemella ocorre principalmente na região Norte de São Paulo, estendendo-se ao Sul até a capital, preferencialmente em campos limpos ou áreas onde haja uma perturbação antrópica (Fig. 2).

Observações feitas no campo mostraram que Zornia gemella se reproduz também vegetativamente formando densas populações, diferentemente do que ocorre por exemplo com Z. reticulata. Citada também para a Bahia, Minas Gerais, Rio de Janeiro e Rio Grande do Sul, além dos Estados Unidos, Costa Rica, Cuba, Jamaica, Martinica, Guiana Francesa, Guiana Inglesa, Suriname, Venezuela, Paraguai e Argentina (Mohlenbrock 1961).

Material Examinado: São Paulo: Amparo, 15/XII/1942, M. Kuhlmann 34, fl. (SP); Botucatu, 8/XI/1993, A. Sciamarelli et al. 28959, fl. (UEC); Campinas, 28/1I/1936, J. Santoro s/n, fl., fr. (ESA); Campinas, 6/XI/1938, A.P. Viegas et. al., fl., fr. (SP 1853); Campinas, 29/X/1938, A.P. Viegas \& G.P. Viegas, fl. (SP 2485); Campinas, 20/II/ 1976, H.F. Leitão Filho 1789 \& J. Semir, fr. (UEC); Itatiba, 20/II/1971, H.F. Leitão Filho 1123, fl., fr. (IAC); Itatiba, 4/IV/1978, P.R. Salgado et al. IZ-323, fr. (UEC); Santa Rita, 9/II/1977, G. Bufarah et al. IZ-064, fr. (UEC); São Paulo, 12/III/1930, F.C. Hoehne, fl. (SP 25207); São Paulo, 2/III/1961, C.G. Fonseca 28, fl., fr. (SP). 
Das 11 espécies citadas na literatura para o Estado de São Paulo, sete foram analisadas (Zornia virgata, Z. cryptantha, Z. ramboiana, Z. reticulata, Z. latifolia, Z. curvata, Z. gemella) e três, $Z$. vestita., $Z$. pardina var. pardina e $Z$. orbiculata, não tiveram sua ocorrência confirmada. Nos casos de $Z$. pardina e Z. vestita, elas foram identificadas $\operatorname{com} Z$. reticulata $\mathrm{e} Z$. cryptantha, respectivamente, devido à sobreposição dos caracteres morfológicos apresentados pelos espécimes analisados com os destas espécies. Foram examinados inclusive alguns dos paratipos de $Z$. pardina (Brasil, SP, Campinas, 7 e 16 /XI/1935, W.G.Howk 39 e 50 - US) que foram identificados com Z. reticulata o isotipo de Z. vestita (Brasil, SP, Mogi Guaçu, G.A. Black 51-11117 - IAN) que apresentou os caracteres diagnósticos (forma e tamanho das bractéolas e tipo de indumento) como um extremo da variação aceita para $Z$. cryptantha. A exsicata identificada como Z orbiculata e citada por Rocha et al. (1979) como ocorrente no Estado de São Paulo, foi determinada como Z. reticulata.

Zornia paniculata N.F.Mattos, descrita por Mattos (1975), é uma espécie que apresenta características que se enquadram na circunscrição de $Z$. virgata, sendo considerada um sinônimo taxonômico.

Além destas, foi registrada a ocorrência de Z. glabra e de Z. gardneriana, esta última tendo sido introduzida e atualmente apresentando-se como subespontânea em áreas do município de Matão.

Em São Paulo, o gênero tem boa representatividade, pois explora desde a região litorânea até a divisa com Mato Grosso do Sul. Ocupa preferencialmente formações campestres, de campos limpos a cerrados "sensu latu", em áreas de transição entre algumas formas de vegetação e, mais raramente, em restingas e campos de altitude. É comum em gramados e beira de estradas e algumas de suas espécies apresentam características de plantas invasoras.

Zornia reticulata, Z.glabra, Z. latifolia, Z. gemella e Z. curvata são espécies polimórficas e compõem o complexo Zornia diphylla sensu Bentham.

Bentham (1859) avaliou todas as espécies de Zornia J.F. Gmel. descritas no mundo até então, chegando à conclusão que havia um conjunto de espécies muito próximas morfologicamente, que estariam melhor agrupadas ao nível de variedades de uma única espécie. As características anteriormente utilizadas nas delimitações específicas foram consideradas por ele como contínuas e adequadas para o reconhecimento de variedades. Bentham (1859) utilizou para separá-las principalmente a forma e o tamanho dos folíolos e a quantidade de pontuações nas bractéolas e deu pouca relevância às flores e aos frutos (Tab. 1). Dentre as 14 variedades de $Z$. diphylla reconhecidas por Bentham (l.c.) não constam caracteres do fruto para 5 delas, para outras 5 foi referido como possuindo características idênticas às de alguma outra variedade, 2 das quais distinguindo-se apenas no tamanho e quantidade de pontuações. Da mesma forma, 3 variedades não receberam referência alguma quanto aos caracteres florais e para outras 9 existem apenas informações quanto ao comprimento da flor e além disso algumas são referidas como iguais às outras nesse caráter.

Mohlenbrock (1961) restabeleceu várias espécies, antes consideradas como 


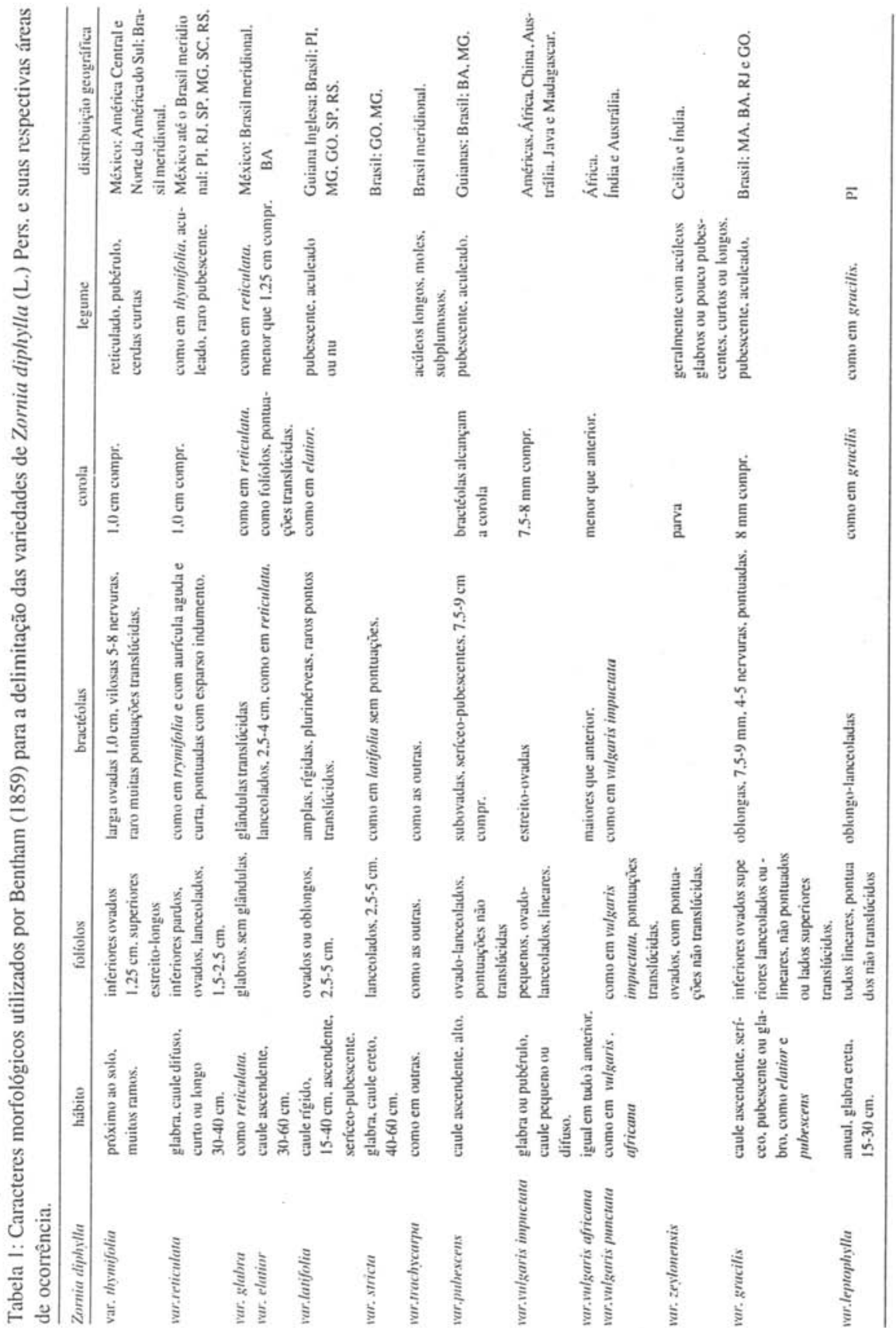


entidades taxonômicas infra específicas, e utilizou, basicamente, características morfológicas de frutos, cálice e bractéolas para estabelecer e separar espécies. Todavia, para alguns grupos não existe uma avaliação abrangente da amplitude de variações aceita dentro dos limites específicos.

As espécies do grupo Zornia diphylla "sensu Bentham" ocorrentes em São Paulo não mostraram características morfológicas descontínuas que permitissem seu pronto reconhecimento. Os caracteres diagnósticos são tênues, sugerindo a necessidade de uma reavaliação do conceito taxonômico destas espécies.

\section{Agradecimentos}

Aos curadores e funcionários dos herbários BOTU, ESA, F, HB, HRCB, IAC, $\mathrm{RB}, \mathrm{R}, \mathrm{SP}, \mathrm{SPF}$, UEC e US pelo empréstimo do material; à Coordenadoria de Aperfeiçoamento ao Ensino Superior (CAPES), pela concessão da Bolsa de Mestrado e à Sra. Esmeralda Z . Borghi pelo acabamento a nanquim das ilustrações.

\section{Referências bibliográficas}

Aranha, C.; Bacchi, O. \& Leitão Filho, H. de F. 1972. Plantas invasoras de culturas. São Paulo, Hucitec. v.2.

Arechavaleta, J. 1901. Flora Uruguaia. An. Mus. Nac. Montevideo 3: 358-363.

Bacigalupo, N.M. \& Troncoso, N.S. 1977. Plantas vasculares nuevas e interessantes de la Flora de Entre Rios, III. Darwiniana 21: 172-181.

Bentham, G. 1859. Papilionaceae. In Martius, C.F.P.; Endlicher, S. \& Fenzl, E. (ed.), Flora Brasiliensis. Lipsiae, Frid. Fleisher. v. 15, part.1.

Burkart, A. 1939. Las Leguminosas Hedysareas de La Republica Argentina y Regiones Adyacentes. Darwiniana 3: 117-301.

Burkart, A. 1952. Las Leguminosas Argentinas Silvestres y Cultivadas. ed. 2. Buenos Aires, Acme.

Chodat, R.H. \& Hassler, E. 1904. Plantae Hasslerianae. Bull. Herb. Boissier, ser. 2, 4: 887-888.

De Candolle, A.P. 1825. Leguminosae. In A.P. De Candolle, Prodomus Systematics Naturalis Regni vegetabilis., Paris, Treuttel \& Wurtz.v.2.

Fawcett, W. \& Rendle, A.B. 1920. Flora da Jamaica. London, British Museum, v. 4.

Gmelin, J.F. 1791. Systema Naturae per regna tria naturae, secundum classes, ordines, genera, species, cum characteribus, differentiis. Georg Emanuel Beer, Leipzig.

Lewis, G.P. 1987. Legumes of Bahia. Royal Botanic Garden, Kew.

Lewis, G.P. \& Owen, P.E. 1989. Legumes of the Ilha de Maracá. Royal Botanic Garden Kew.

Lorenzi, H. 1982. Plantas daninhas do Brasil: terrestres, aquáticas, parasitas, tóxicas e medicinais. Nova Odessa.

Malme, G.O.A. 1931. Die leguminosen der zweiten Regnellschen Reise. Ark. Bot. 23A(13): 75.

Mattos, N.F. 1975. Novidades taxonômicas em plantas do Brasil. Loefgrenia 63(3): 68.

Mohlenbrock, R. 1961. A monograph of the Leguminous genus Zornia. Webbia 16(1): 1-141.

Moricand, M.E. 1844. Plantes nouvelles d'Amérique. Genève, Jules-GmeFick. v. 8.

Radford, A.E.; Dickison, W.C.; Massey, J.R. \& Bell, C.R. 1974. Vascular plant Systematics. Harper \& Row, New York.

Reynolds, S.T. \& Holland, A.E. 1989. The genus Zornia J.F.Gmel. (Leguminosae) in Australia. Austrobaileya 3: 13-38.

Rocha, G. L.; Leitão Filho, H. de F.; Andrade, J.B.; Shepherd, G.J.; Kinoshita-Gouvea, L.S.; Taroda, N.; Gibbs, P.E.; Tamashiro, J.; Monteiro, R.; Alcantara, P.B.; Bufarah, G.; Oliveira, P.O.P. de; Alcantara, V.B.G.; Almeida, J.E.; Salgado, P.R.; Puls, F.S.; Sigrist, J.M.M.; Fonseca, T.C. \& 
Paulino, V.T. 1979. Coleta, identificação e distribuição de leguminosas forrageiras tropicais brasileiras- Brasil central-Fase I (1). Boletim da Indústria animal 36: 255-324.

Sciamarelli, A. 1994. Zornia J.F.Gmel. (Leguminosae-Papilionoideae-Aeschynomeneae) no Estado de São Paulo. Dissertação de Mestrado, Campinas, Instituto de Biologia da Universidade Estadual de Campinas.

Smith, J.E. 1819. Cyclopedia. London. Longman, Hurst, Res, Orme \& Brown. v. 39.

Vanni, R.O. 1981. Novidades en Hedysareae (Leguminosae-Papilionoideae). Bonplandia 20(5): 175-188.

Velazquez, D. \& Orsini, G. 1991. Catalog and description of the genera of the subfamily Papilionoideae

(Leguminosae) in Venezuela: I Tribes Abreae, Aeschynomeneae and Amorpheae. Ernstia I: 21-38.

Vogel, J.R.T. 1838. De Hedysareis Brasiliae. Linnaea 12: 58.

Turril, W.B. \& Milne-Redhead, M.A. 1956. Flora of tropical East Africa. London, Crown agents for oversea governments and administrations. 